Cochrane Database of Systematic Reviews

\title{
Routine or selective carotid artery shunting for carotid endarterectomy (and different methods of monitoring in selective shunting) (Review)
}

Chongruksut W, Vaniyapong T, Rerkasem K

Chongruksut W, Vaniyapong T, Rerkasem K.

Routine or selective carotid artery shunting for carotid endarterectomy (and different methods of monitoring in selective shunting).

Cochrane Database of Systematic Reviews 2014, Issue 6. Art. No.: CD000190.

DOI: 10.1002/14651858.CD000190.pub3.

www.cochranelibrary.com

Routine or selective carotid artery shunting for carotid endarterectomy (and different methods of monitoring in selective shunting) (Review) 
TABLE OF CONTENTS

HEADER 1

ABSTRACT

PLAIN LANGUAGE SUMMARY

BACKGROUND

OBJECTIVES

METHODS

RESULTS

Figure 1.

DISCUSSION

AUTHORS' CONCLUSIONS

ACKNOWLEDGEMENTS

REFERENCES

CHARACTERISTICS OF STUDIES

DATA AND ANALYSES

Analysis 1.1. Comparison 1 Shunting (routine or selective) versus no shunting, Outcome 1 Death from all causes within 30 days of surgery.

Analysis 1.2. Comparison 1 Shunting (routine or selective) versus no shunting, Outcome 2 Stroke-related death within 30 days of surgery (best case).

Analysis 1.3. Comparison 1 Shunting (routine or selective) versus no shunting, Outcome 3 Stroke-related death within 30 days of surgery (worst case).

Analysis 1.4. Comparison 1 Shunting (routine or selective) versus no shunting, Outcome 4 Any stroke during surgery (best case).

Analysis 1.5. Comparison 1 Shunting (routine or selective) versus no shunting, Outcome 5 Any stroke during surgery (worst case).

Analysis 1.6. Comparison 1 Shunting (routine or selective) versus no shunting, Outcome 6 Any stroke within 24 hours of surgery.

Analysis 1.7. Comparison 1 Shunting (routine or selective) versus no shunting, Outcome 7 Any stroke within 30 days of surgery.

Analysis 1.8. Comparison 1 Shunting (routine or selective) versus no shunting, Outcome 8 Ipsilateral stroke during surgery (best case).

Analysis 1.9. Comparison 1 Shunting (routine or selective) versus no shunting, Outcome 9 Ipsilateral stroke during surgery (worst case).

Analysis 1.10. Comparison 1 Shunting (routine or selective) versus no shunting, Outcome 10 Ipsilateral stroke within 30 days of surgery (best case).

Analysis 1.11. Comparison 1 Shunting (routine or selective) versus no shunting, Outcome 11 Ipsilateral stroke within 30 days of surgery (worst case).

Analysis 1.12. Comparison 1 Shunting (routine or selective) versus no shunting, Outcome 12 Stroke or death within 30 days of surgery (best case).

Analysis 1.13. Comparison 1 Shunting (routine or selective) versus no shunting, Outcome 13 Stroke or death within 30 days of surgery (worst case).

Analysis 1.14. Comparison 1 Shunting (routine or selective) versus no shunting, Outcome 14 Haemorrhage from operation site.

Analysis 1.15. Comparison 1 Shunting (routine or selective) versus no shunting, Outcome 15 Infection of operation site. ........

Analysis 1.16. Comparison 1 Shunting (routine or selective) versus no shunting, Outcome 16 Nerve palsy post-operatively. .... APPENDICES

WHAT'S NEW

HISTORY

CONTRIBUTIONS OF AUTHORS

DECLARATIONS OF INTEREST

SOURCES OF SUPPORT

DIFFERENCES BETWEEN PROTOCOL AND REVIEW

NOTES

INDEX TERMS

1

2

3

4

4

6

Routine or selective carotid artery shunting for carotid endarterectomy (and different methods of monitoring in selective shunting) 
[Intervention Review]

\section{Routine or selective carotid artery shunting for carotid endarterectomy (and different methods of monitoring in selective shunting)}

Wilaiwan Chongruksut ${ }^{1}$, Tanat Vaniyapong ${ }^{1}$, Kittipan Rerkasem ${ }^{1,2}$

1Department of Surgery, Faculty of Medicine, Chiang Mai University, Chiang Mai, Thailand. 2Center for Applied Science, Research Institute of Health Sciences, Chiang Mai University, Chiang Mai, Thailand

Contact address: Kittipan Rerkasem, Department of Surgery, Faculty of Medicine, Chiang Mai University, Chiang Mai, 50200, Thailand. rerkase@gmail.com.

Editorial group: Cochrane Stroke Group

Publication status and date: New search for studies and content updated (no change to conclusions), published in Issue 6, 2014.

Citation: Chongruksut W, Vaniyapong T, Rerkasem K. Routine or selective carotid artery shunting for carotid endarterectomy (and different methods of monitoring in selective shunting). Cochrane Database of Systematic Reviews 2014, Issue 6. Art. No.: CD000190. DOI: 10.1002/14651858.CD000190.pub3.

Copyright @ 2014 The Cochrane Collaboration. Published by John Wiley \& Sons, Ltd.

\section{A B S T R A C T}

\section{Background}

Temporary interruption of cerebral blood flow during carotid endarterectomy can be avoided by using a shunt across the clamped section of the carotid artery. This may improve outcome. This is an update of a Cochrane review originally published in 1996 and previously updated in 2009.

\section{Objectives}

To assess the effect of routine versus selective or no shunting during carotid endarterectomy, and to assess the best method for selecting people for shunting.

\section{Search methods}

We searched the Cochrane Stroke Group Trials Register (last searched August 2013), the Cochrane Central Register of Controlled Trials (CENTRAL) (The Cochrane Library, 2013, Issue 8), MEDLINE (1966 to August 2013), EMBASE (1980 to August 2013) and Index to Scientific and Technical Proceedings (1980 to August 2013). We handsearched journals and conference proceedings, checked reference lists, and contacted experts in the field.

\section{Selection criteria}

Randomised and quasi-randomised trials of routine shunting compared with no shunting or selective shunting, and trials that compared different shunting policies in people undergoing carotid endarterectomy.

\section{Data collection and analysis}

Three review authors independently performed the searches and applied the inclusion criteria. For this update, we identified two new relevant randomised controlled trials.

\section{Main results}

We included six trials involving 1270 participants in the review: three trials involving 686 participants compared routine shunting with no shunting, one trial involving 200 participants compared routine shunting with selective shunting, one trial involving 253 participants compared selective shunting with and without near-infrared refractory spectroscopy monitoring, and the other trial involving 131 participants compared shunting with a combination of electroencephalographic and carotid pressure measurement with shunting by carotid pressure measurement alone. In general, reporting of methodology in the included studies was poor. For most studies, the blinding

Routine or selective carotid artery shunting for carotid endarterectomy (and different methods of monitoring in selective shunting) 
of outcome assessors and the report of prespecified outcomes were unclear. For routine versus no shunting, there was no significant difference in the rate of all stroke, ipsilateral stroke or death up to 30 days after surgery, although data were limited. No significant difference was found between the groups in terms of postoperative neurological deficit between selective shunting with and without near-infrared refractory spectroscopy monitoring, However, this analysis was inadequately powered to reliably detect the effect. There was no significant difference between the risk of ipsilateral stroke in participants selected for shunting with the combination of electroencephalographic and carotid pressure assessment compared with pressure assessment alone, although again the data were limited.

\section{Authors' conclusions}

This review concluded that the data available were too limited to either support or refute the use of routine or selective shunting in carotid endarterectomy. Large scale randomised trials of routine shunting versus selective shunting are required. No method of monitoring in selective shunting has been shown to produce better outcomes.

\section{PLAIN LANGUAGE SUMMARY}

Routine or selective carotid artery shunting for carotid endarterectomy (and different methods of monitoring in selective shunting) Question

We wanted to compare the effect of routine shunting versus selective or no shunting during carotid endarterectomy, and to assess the effect of different methods for selection of people for shunting.

\section{Background}

About $20 \%$ of strokes result from narrowing of the carotid artery (the main artery supplying blood to the brain). Carotid endarterectomy is an operation to remove this narrowing and therefore reduce the risk of stroke. However, there is a $5 \%$ to $10 \%$ risk of the operation itself causing a stroke. The use of a silicon tube, or shunt, as a temporary bypass can reduce the length of time that blood flow to the brain is interrupted during the operation. This may reduce the risk of perioperative stroke but could also result in arterial wall damage and therefore increase the risk of stroke. Shunt surgery falls into three categories. Firstly, in routine shunting, the surgeon inserts a shunt in every patient. Secondly, in selective shunting, the surgeon only uses a shunt in patients with an inadequate blood supply to the brain following clamping; various cerebral monitoring techniques, such as ultrasound for predicting who needs a shunt, have been used in this policy. Thirdly, in no shunting, surgeons do not employ shunts at all.

\section{Study characteristics}

We identified six studies up to August 2013, for inclusion in the review. These studies included a total of 1270 participants. Three of the trials compared routine shunting with no shunting, one trial compared routine shunting versus selective shunting, and another two trials compared different methods of monitoring in selective shunting. We have not yet identified any trials that compared selective shunting with no shunting. All the included trials assessed the use of shunting in people undergoing endarterectomy under general anaesthetic. The age of the participants ranged from 40 to 89 years, and overall, there were more male than female participants. Where reported, participants were followed up for no longer than 30 days.

\section{Key results}

There is still no evidence for the use of a carotid shunt during carotid endarterectomy. This review suggests a benefit from the use of a shunt, but the overall results were not statistically significant. More trials are needed.

\section{Quality of the evidence}

There were significant problems with the quality of the randomised trials and, overall, the reporting of study methodology was poor. 


\section{B A C K G R O U N D}

\section{Description of the condition}

Around $20 \%$ of people presenting with a transient ischaemic attack (TIA) or non-disabling stroke have significant stenosis with unstable atheromatous plaque at or around the bifurcation of the ipsilateral carotid artery. This plaque can lead to the formation of emboli, which may cause a stroke. Carotid endarterectomy is an operation to remove this stenosis together with unstable plaque and, therefore, decrease the risk of stroke.

\section{Description of the intervention}

Carotid endarterectomy has been shown in large, well-conducted randomised controlled trials (RCTs) to substantially reduce the relative risk of stroke in people with recent TIAs or minor strokes related to severe symptomatic carotid artery stenosis (ECST 1991; NASCET 1991; Rerkasem 2011). To a lesser extent, benefit has also been shown for moderate symptomatic carotid artery stenosis (Rerkasem 2011). In these trials, the benefits were seen despite a stroke and death rate, within 30 days of the operation, of between $5 \%$ to $10 \%$. Most of these strokes occurred during, or within, a few days of surgery, and were presumably related to surgery. More recently, it has been shown that people with asymptomatic carotid artery stenosis of greater than $60 \%$ may also benefit from carotid endarterectomy, but this relies on an average 30-day stroke and death rate of $3 \%$ or less (ACAS 1995; ACST 2004). Reducing the risk of perioperative stroke and death should therefore increase the number of people who can benefit from carotid endarterectomy. Most of the perioperative strokes are ischaemic and some (especially those that occur during the operation) may be caused by the temporary interruption of blood flow during the procedure whilst the carotid artery is clamped. This reduction in blood flow should be avoided if an intraluminal shunt is placed across the clamped section of the artery and this may reduce the perioperative stroke rate. When carotid endarterectomy is performed under local anaesthetic about $10 \%$ to $20 \%$ of people develop a transient neurological deficit after the artery is clamped, in which case the vast majority of surgeons would regard a shunt as mandatory. However, the routine or selective use of intraluminal shunting in carotid endarterectomy under general anaesthetic is more controversial. The publication of the results of the GALA trial has shown that the operative risk of stroke and death due to endarterectomy under local anaesthetic versus general anaesthetic is similar and so many operations will continue to be done under general anaesthetic (Lewis 2008).

\section{How the intervention might work}

Some advocate that routine shunting for all operations be done under general anaesthetic on the assumption that it reduces the risk of perioperative ischaemic strokes; it may also reduce the risk of minor cerebral ischaemic damage, and it also allows the surgeon time to perform an unhurried carotid endarterectomy or to teach a trainee carefully and in an unhurried manner (Javid 1979; Thompson 1979). Others advocate the selective use of shunting only in people who are at high risk of developing cerebral ischaemia during carotid clamping, but there is no consensus on how to identify which people need a shunt. Methods used to select which people to shunt include: using preoperative features such as a previous ipsilateral stroke or a contralateral carotid occlusion (Buche 1988); using indirect assessments of cerebral blood flow during the operation by monitoring electroencephalographic (EEG) activity (Whittemore 1983), somatosensory evoked potentials (SEP) (Schweiger 1988), carotid stump back pressure (Ricotta 1983), or combinations of these; using direct assessments of cerebral blood flow during the operation using intra-arterial radio-labelled xenon (Sundt 1986), or transcranial Doppler (Steiger 1989); and assessing the development of new neurological signs in awake patients who have their endarterectomy performed under local anaesthetic (Benjamin 1993; Connolly 1977; Evans 1985).

None of these monitoring techniques are perfect. Studies in people having endarterectomies performed under local anaesthetic have shown that both EEG monitoring and carotid stump pressure assessment may be normal in $6 \%$ to $30 \%$ of those who develop neurological signs and that they may be abnormal in 3\% to $11 \%$ of those who do not develop signs of ischaemia (Benjamin 1993; Connolly 1977; Evans 1985). Many of these techniques also require additional technology and expert interpretation and so may not be practical in many situations. In addition, shunting may be associated with complications such as air embolism, plaque embolism, dissection of the carotid artery, acute occlusion of the carotid artery, and it also lengthens the time of the procedure and may make it technically more difficult (Green 1985; Ott 1980). All of these factors may be associated, paradoxically, with an increased risk of perioperative stroke (Salvian 1997). Several authors have, therefore, argued that shunting should be avoided (Ott 1980; Prioleau 1977; Reddy 1987). Shunting could also be associated with other complications due to increased manipulation of the artery such as an increased risk of cranial nerve palsy (Forssell 1995), arterial haemorrhage or infection, or long-term restenosis, perhaps because of intimal damage leading to intimal hyperplasia (Ouriel 1987), but accurate data on these risks are limited at present.

\section{Why it is important to do this review}

The lack of good evidence to support the use of shunts is reflected by a considerable variation in surgical practice. For UK surgeons ( $\mathrm{N}=$ 76) performing carotid endarterectomy under general anaesthesia, a shunt was always, never, or selectively used by $73.6 \%, 4.2 \%$ and $22.2 \%$ respectively (Girn 2008). An earlier survey from North America showed that about one-third of carotid endarterectomies were performed with routine shunting, one-third with selective shunting and one-third without shunting (Fode 1986). Data from the European Carotid Surgery Trialists (ECST) showed highly significant variation in shunting practices for endarterectomy done under general anaesthetic both between individual surgeons and between countries (both $P<0.001$ ) (Bond 2002). For example, shunts were used in $89 \%$ of operations performed in Germany versus $41 \%$ performed in Finland and $1 \%$ of those performed in France.

The best way to determine the perioperative (and long-term) risks and benefits of shunting during carotid endarterectomy is to compare shunting with no shunting in RCTs. We, therefore, reviewed all such trials, and the trials comparing different methods of selecting which people under general anaesthetic require selective shunting. A comparison of local versus general anaesthetic is dealt with in a separate review (Vaniyapong 2013).

This is an update of a Cochrane Review originally published in 1996 and previously updated in 2009. 


\section{O B JECTIVES}

To assess the effect of routine versus selective or no shunting during carotid endarterectomy, and to assess the best method for selecting people for shunting. Specifically, to:

1. determine whether a policy of routine or selective shunting reduces the risk of perioperative stroke or death following carotid endarterectomy;

2. determine whether a policy of routine or selective shunting increases the complication rate (other than stroke or death) following carotid endarterectomy;

3. determine whether a policy of routine or selective shunting is associated with an increased risk of restenosis and, therefore, perhaps of stroke during long-term follow-up;

4. to assess the effect of different methods for selection of people for shunting.

Our primary hypothesis was that shunting reduced the risk of perioperative stroke but may be associated with an increased risk of other complications.

\section{METHODS}

\section{Criteria for considering studies for this review Types of studies}

We included all unconfounded RCTs and quasi-RCTs that compared shunting with no shunting, or one method of monitoring with another in selective shunting. Since foreknowledge of treatment allocation can bias the results of randomised trials (Schulz 1995), where there were sufficient data, we planned to perform sensitivity analyses including only trials where treatment allocation was securely concealed.

\section{Types of participants}

Trials that included any person undergoing unilateral or bilateral carotid endarterectomy (whether it was for symptomatic or asymptomatic carotid disease) were eligible.

\section{Types of interventions}

The following types of trials were eligible.

1. Trials comparing a policy of routine shunting in all participants using any type of carotid shunt with a policy of avoiding a shunt (never shunting).

2. Trials comparing a policy of selective shunting in only those participants identified as being at risk of cerebral ischaemia with a policy of avoiding a shunt. People could be identified as being at risk of ischaemia either on the basis of preoperative assessment (e.g. recent stroke), or assessment during the operation (e.g. assessment of stump pressure or EEG monitoring or near-infrared spectroscopy (NIRS) during a period of arterial occlusion).

3. Trials comparing a policy of selective shunting with routine shunting.

4. Trials in which participants were shunted selectively under general anaesthetic and that compared one method of assessment versus another to identify which people required a shunt.

\section{Types of outcome measures}

The intended measures of outcome were:

1. all strokes (ischaemic and haemorrhagic) that occurred during the operation (i.e. stroke apparent on recovery from anaesthetic), within 24 hours of surgery, within 30 days of surgery, and during the whole of follow-up. We did not include TIAs because these are less important to patients since they do not result in chronically impaired function. They are also more difficult to diagnose reliably, and so there is more potential for bias in their assessment (particularly if this is unblinded);

2. all ipsilateral strokes (ischaemic and haemorrhagic) that occurred within 24 hours and 30 days of surgery and during the whole of follow-up;

3. death from any cause within 30 days of surgery and during follow-up;

4. other complications within 30 days of surgery, such as rupture or haemorrhage from the endarterectomy site, infection of the wound or artery, occlusion of the artery operated on, or ipsilateral nerve palsies;

5. long-term arterial complications, such as restenosis of the operated artery;

6. cognitive function at the end of follow-up.

\section{Search methods for identification of studies}

See the 'Specialized register' section in the Cochrane Stroke Group module. We searched for trials published in all languages and arranged translation of all possibly relevant non-English language publications.

\section{Electronic searches}

We searched the Cochrane Stroke Group Trials Register (last searched in August 2013), the Cochrane Central Register of Controlled Trials (CENTRAL) (The Cochrane Library 2013, Issue 8) (Appendix 1), MEDLINE (Ovid) (1966 to August 2013) (Appendix 1) and EMBASE (Ovid) (1980 to August 2013) (Appendix 2). We developed the search strategies with the help of the Cochrane Stroke Group Trials Search Co-ordinator.

We also systematically searched the conference proceedings database Index to Scientific and Technical Proceedings (ISTP) (BIDS) (1980 to August 2013) using the terms 'carotid' and 'trial or random*'.

\section{Searching other resources}

1. We handsearched the following journals:

a. Annals of Surgery (1981 to 30 August 2013);

b. Annals of Vascular Surgery (1994 to 30 August 2013);

c. Vascular (previously Cardiovascular Surgery) (1994 to 30 August 2013);

d. European Journal of Vascular and Endovascular Surgery (previously European Journal of Vascular Surgery) (1987 to 30 August 2013);

e. Journal of Vascular Surgery (1994 to 30 August 2013);

f. Stroke (1994 to 30 August 2013).

2. We reviewed the reference lists of all relevant studies.

3. We contacted experts in the field to identify further published and unpublished studies.

Routine or selective carotid artery shunting for carotid endarterectomy (and different methods of monitoring in selective shunting) 
4. For a previous version of the review we handsearched the following journals and conference proceedings:

a. American Journal of Surgery (1994 to 2001);

b. British Journal of Surgery (1985 to 2001);

c. World Journal of Surgery (1978 to 2001).

d. AGM of the Vascular Surgical Society (UK) (1995 to 2001);

e. AGM of the Association of Surgeons of Great Britain and Ireland (1995 to 2001);

f. AHA Stroke Conference (1995 to 2001);

g. Annual Meeting of the Society for Vascular Surgery (USA) (1995 to 2001);

h. European Stroke Conference (1995 to 2001).

\section{Data collection and analysis}

All three review authors (WC, TV, KR) independently collected data. We collected the details of methods, participants, setting, context, interventions, outcomes, results, publications and investigators. We performed meta-analysis using RevMan 5.2 (RevMan 2012)

\section{Selection of studies}

All three review authors (WC, TV, KR) independently read the titles and abstracts of the records obtained from the electronic searches and excluded obviously irrelevant studies. We obtained the full texts of the remaining papers and the same authors independently selected studies for inclusion based on the predefined criteria. We resolved any disagreements through discussion.

\section{Data extraction and management}

We extracted details of the method of randomisation, the blinding of outcome assessments, losses to follow-up, crossovers and exclusions after randomisation from the publications. We also compared participant characteristics (age, sex, vascular risk factors, indication for surgery) and details of the operation (type of cerebral monitoring, use of carotid patching, anaesthetic technique, use of perioperative antiplatelet therapy) between the treatment groups in each trial. Also, although people who were asymptomatic were included in some studies, the data were not available in sufficient detail to allow separate analysis of the outcomes of carotid endarterectomy in people with symptoms and those without symptoms. However, it is unlikely that the relative effect of shunting versus no shunting varied qualitatively with symptom status.

\section{Assessment of risk of bias in included studies}

We assessed risk of bias into three categories: low risk, high risk, and unclear risk in the 'Risk of bias' tables, as described in the Cochrane Handbook for Systematic Reviews of Interventions (Higgins 2011). These risks of bias included random sequence generation (selection bias), allocation concealment (selection bias), blinding (performance bias and detection bias), blinding of participants and personnel (performance bias), blinding outcome assessment (detection bias), and incomplete outcome data (attrition bias).

\section{Measures of treatment effect}

We measured the treatment effect in the following outcomes within 30 days of surgery: stroke, death, myocardial infarction, local haemorrhage, cranial nerve injuries, and shunted arteries.

\section{Unit of analysis issues}

The unit of analysis is the onset of the adverse outcome. We extracted details of all the outcome events. Some studies included participants who had bilateral operations, but only reported the number of participants, and not the number of arteries, in each group. However, since bilateral carotid endarterectomy was unusual, we used the number of participants as the number of operations in such studies. Where possible we used the number of participants, not the number of arteries in the analysis. The unit of analysis was presented as odds ratios (OR).

\section{Dealing with missing data}

When data were missing, we contacted the corresponding author or co-author through the address given in the publication. If this information was not available, we searched for the study group via the Internet and contacted them for the missing data.

\section{Assessment of heterogeneity}

We assessed heterogeneity between study results using the 12 statistic (Higgins 2003). We examined the percentage of total variations across the studies due to heterogeneity rather than to chance. Values of $\mathrm{I}^{2}$ over $75 \%$ indicated a high level of heterogeneity.

We used 12 methods for quantifying inconsistency across studies. A rough index to interpretation is as follows:

- $0 \%$ to $40 \%$ : might not be important;

- $30 \%$ to $60 \%$ : may represent moderate heterogeneity;

- $50 \%$ to $90 \%$ : may represent substantial heterogeneity;

- $75 \%$ to $100 \%$ : considerable heterogeneity.

\section{Assessment of reporting biases}

We identified all relevant trials, including unpublished trials, by searching not only MEDLINE and EMBASE, but also the Cochrane Stroke Group Trials Register. In addition, we handsearched relevant journals and reviewed the reference lists of all relevant studies. We also contacted experts in this field. We searched for trials published in all languages and arranged translation of all possibly relevant non-English language publications.

\section{Data synthesis}

We calculated proportional risk reductions based on a weighted estimate of the OR using the Peto method (APT 1994).

\section{Subgroup analysis and investigation of heterogeneity}

If there was considerable heterogeneity, we investigated the cause for such interactions.

\section{Sensitivity analysis}

When the decisions for the process undertaken in this systematic review were somewhat arbitrary or unclear, we undertook sensitivity analyses. For example, we performed both fixed-effect and random-effects meta-analyses to evaluate the consistency of the results, or we compared pooled estimates of all studies' results with the results of the excluded lower quality studies. 


\section{RESULTS}

\section{Description of studies}

\section{Results of the search}

For this review we updated our previous searches of the Cochrane Stroke Group Trials Register, MEDLINE, EMBASE and ISTP. We also searched CENTRAL. We reviewed a total of 2853 references from the searches and obtained the full paper copy of 33 trial reports. We identified two new RCTs (AbuRahma 2010; Zogogiannis 2011). We identified a third RCT that compared the outcome of endarterectomy using one of two different types of shunt, the Pruitt-Inahara and Javid shunts (Wilkinson 1997), but this did not meet the inclusion criteria and so we disregarded it. This will be a topic of another review.

\section{Included studies}

In the included six trials, we identified three trials (including 686 participants) that compared routine shunting with no shunting (Gumerlock 1988; Palombo 2007; Sandmann 1993). One RCT compared the results of routine shunting versus selective shunting based on stump pressure. Two hundred participants were randomised into routine shunting (98 participants) or selective shunting (102 participants). In the selective shunting group, shunting was used only if systolic stump pressure was less than 40 $\mathrm{mmHg}$. Clinical and demographic characteristics were comparable in both groups. In the selective shunting group, shunting was used in 29 participants (28\%) (AbuRahma 2010). The other two trials compared monitoring methods in selective shunting: Fletcher 1988 (131 participants) compared the use of EEG monitoring combined with an assessment of the carotid stump back pressure with carotid back pressure assessment alone. In the former group, a shunt was only inserted if both the EEG showed significant ipsilateral change within three minutes of clamping and the carotid pressure was less than $50 \mathrm{mmHg}$, whilst in the latter group a shunt was inserted if the pressure was less than $50 \mathrm{mmHg}$; Zogogiannis 2011 (253 participants) evaluated whether the use of an intraoperative algorithm based on cerebral oximetry with NIRS monitoring, could help in the intraoperative decision for shunt placement, in people undergoing carotid endarterectomy. We have not yet identified any trials that compared selective shunting with no shunting. All trials looked at the use of shunting in people having carotid endarterectomy under general anaesthetic.

\section{Excluded studies}

We did not exclude any trials.

\section{Risk of bias in included studies}

One of the six RCTs was published in a journal as a 'Letter to the editor' (Sandmann 1993). For this study, only limited data from the short letter were available. In general, reporting of methodology was poor. The overall results of the 'Risk of bias' analysis are summarised in Figure 1. 
Figure 1. 'Risk of bias' summary: review authors' judgements about each risk of bias item for each included study.

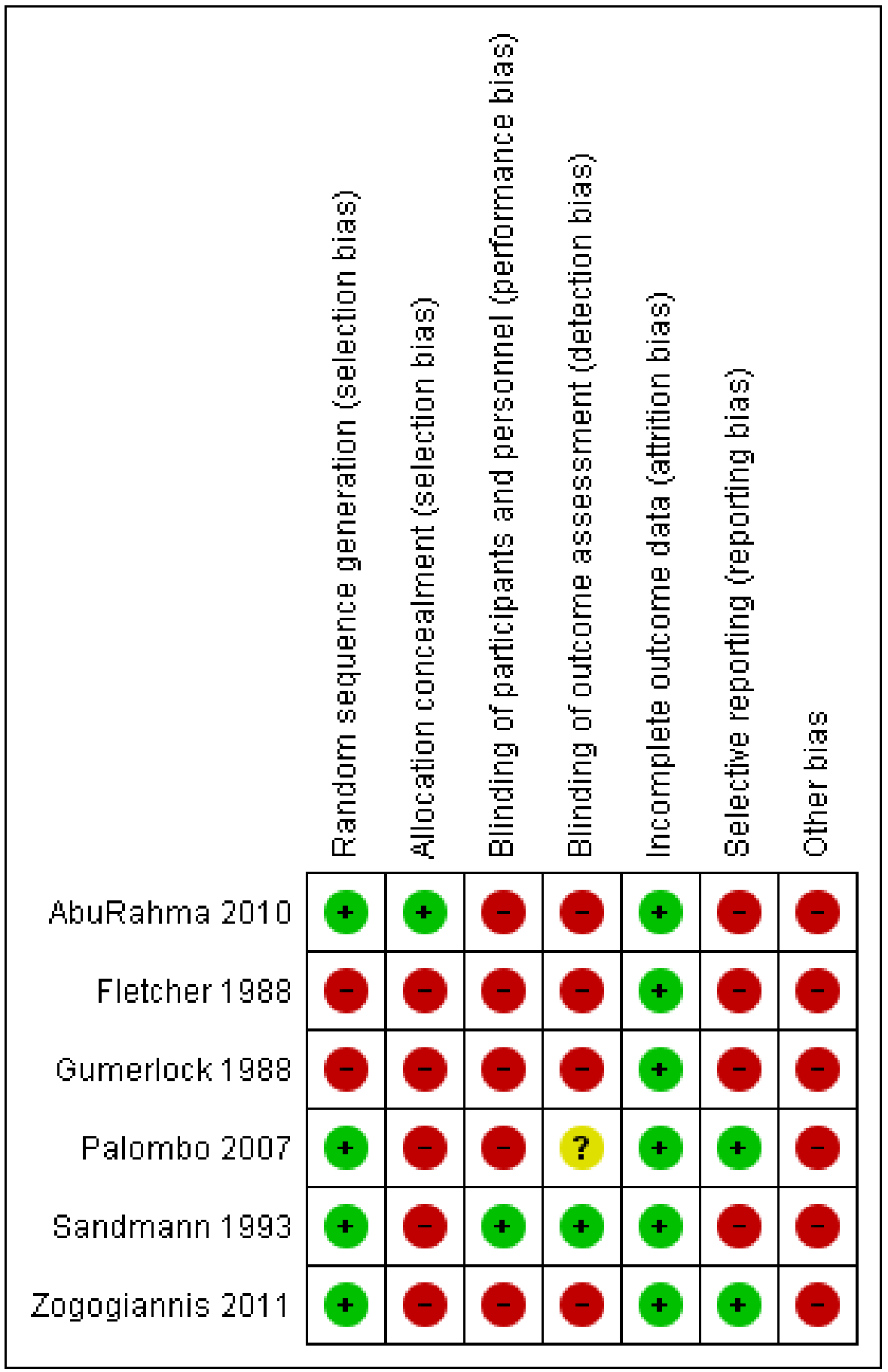

\section{Allocation}

Allocation by randomisation was reported in all studies; however, only three studies reported the method of randomisation. This included odd/even hospital number (Gumerlock 1988), computer randomisation (Palombo 2007), and sequentially-numbered sealed envelopes (Sandmann 1993). The methods used for randomisation in the remaining trials were unclear. Gumerlock 1988 was not truly randomised as it used the patient hospital record number to allocate participants. There was an imbalance in the numbers of participants in each group in this trial (53 shunt versus 65 no shunt), which may have been due to selective inclusion of participants, although it was reported that consecutive patients were entered.

\section{Blinding}

Most studies did not report on blinding of participants, surgical teams and assessors to the randomised treatment allocation. In two trials, outcomes were assessed by independent neurologists (Sandmann 1993) and psychologists (Palombo 2007), but Palombo 2007 did not report whether these independent assessors knew the randomisation code.

Routine or selective carotid artery shunting for carotid endarterectomy (and different methods of monitoring in selective shunting) 


\section{Incomplete outcome data}

Most studies did not report loss-to-follow-up or missing data except Sandmann 1993. There was no available information in this trial to indicate the loss to follow-up. Potentially important outcomes were not measured, such as stroke severity in terms of functional outcome, and long-term restenosis rate. One trial measured postoperative cognitive function (Palombo 2007). In addition, one trial randomised arteries rather than patients (Sandmann 1993), and the number of participants who had only unilateral procedures was not available by treatment group despite contact with the principal trialist. Overall, 441 participants had unilateral procedures and so we had to assume that these participants were roughly equally divided between the two treatment groups (the number of arteries randomised in each group was similar). In this trial the numbers of stroke-related deaths, strokes during surgery, and ipsilateral strokes were not reported by treatment group (and these data were not available from the authors). Therefore, we performed bestand worst-case analyses for these outcomes. This was possible because the total number of each of these events was known, as was the total number of deaths and strokes by treatment group. The best-case analysis assumed that the smallest possible number of events occurred in the shunted group, whilst the worst-case analysis assumed that the smallest number of events occurred in the unshunted group.

\section{Selective reporting}

Most studies did not indicate prespecified outcomes or report all prespecified outcomes. Only two studies reported all expected outcomes that were prespecified (Palombo 2007; Zogogiannis 2011).

\section{Other potential sources of bias}

Regarding allocation concealment, two trials used sealed envelopes that were opened just before surgery (AbuRahma 2010; Sandmann 1993). However, it was not reported if these were opaque. In the other four trials, the method of concealment of allocation was unclear.

We were not able to assess other biases, including measurement bias and funding bias in all studies.

Among the three trials comparing shunt versus no shunt (Gumerlock 1988; Palombo 2007; Sandmann 1993), one trial monitored participants in the unshunted group using EEG and SEP, and during the trial it was decided that participants randomised to no shunt should be shunted if they showed evidence of ipsilateral ischaemia (Sandmann 1993). Hence 3\% of all operations in the no shunt group were in fact performed using a shunt. By comparison, in Gumerlock 1988 and Sandmann 1993 combined, $12 \%$ of the operations that were randomised to the shunt group were performed without shunting for technical reasons (usually because of difficulty in inserting a shunt). The most recent trial used stump pressure measurement and participants with stump pressure less than $50 \mathrm{mmHg}$ required shunting (Palombo 2007).

The treatment groups were generally comparable in two trials (Gumerlock 1988; Palombo 2007). In one trial, those in the shunted group had more severe disease in the contralateral artery, which may have biased the results against shunting (Gumerlock 1988). The comparability of the groups with respect to age, sex, and vascular risk factors were not available for another trial (Sandmann
1993). However, there were imbalances in the surgical technique in this trial. Patching was performed more frequently in the shunted group (57\% versus $39 \%$ ). In addition, plication, resection or vein interposition was performed at the end of the operation to ensure laminar flow on Doppler, and these were performed more frequently in the unshunted group ( $56 \%$ versus $39 \%$ ). This trial also noted that the outcome appeared to be better when the operation was performed by a more senior surgeon, and yet the experience of the surgeons was not given by treatment group. Neither trial reported on whether antithrombotic agents were used pre- or postoperatively.

There were other problems with the trials. Participants undergoing bilateral endarterectomies were included, and in one trial it was possible to be randomised twice to different operations (Sandmann 1993). The results of this trial were reported by artery rather than participant, which made analysis of the results using patientbased denominators (death or any stroke) difficult. Data on the comparability of the participants in this trial were not available and some outcomes were not reported by treatment group.

\section{Effects of interventions}

\section{Shunt versus no shunt}

NB. We had to calculate best- and worst-case scenarios for some outcomes because the number of events in each treatment group was not available for one trial.

\section{Deaths within 30 days of surgery}

The overall risk of deaths in participants who had unilateral operations or bilateral operations using the same procedure was $1.5 \%(10 / 655)$. All deaths were either due to stroke or coronary artery disease. There was a trend favouring a lower death rate in the shunted group but this was not significant (odds ratio (OR) 0.45 , $95 \%$ confidence interval ( $\mathrm{Cl}) 0.13$ to 1.59 ) (Analysis 1.1).

Only four patients died of stroke-related deaths $(0.6 \%)$, so although there was a trend toward fewer stroke deaths in the shunted group, these data were not reliable (best case: Analysis 1.2; worst case: Analysis 1.3).

\section{Any stroke (fatal or non-fatal, ischaemic or haemorrhagic, ipsilateral or contralateral, carotid or vertebrobasilar)}

During surgery, the risk of stroke during surgery in both treatment groups combined was $2.7 \%(18 / 655)$. The best- and worst-case analyses gave qualitatively different results (that is, shunting was associated with a non-significant $58 \%$ reduction or $32 \%$ increase in the odds of stroke respectively) highlighting the instability of the data due to small numbers (best case: Analysis 1.4; worst case: Analysis 1.5).

During surgery or within 24 hours of surgery, data were available from only two trials, of which one trial showed a significant reduction in the risk of stroke with shunting (Gumerlock 1988), and the other trial reported no stroke in either treatment group (Palombo 2007). The pooled result showed a significant reduction in the risk of stroke with shunting (OR $0.15,95 \% \mathrm{Cl} 0.03$ to 0.78 ). However, this result is based on only six strokes in total and so is not reliable (Analysis 1.6).

During surgery or within 30 days of surgery, the overall risk of stroke within 30 days of surgery was $4.0 \%(26 / 655)$. There was a non-

Routine or selective carotid artery shunting for carotid endarterectomy (and different methods of monitoring in selective shunting) 
significant trend towards fewer strokes in the shunted group but the confidence interval was wide (OR $0.77,95 \% \mathrm{Cl} 0.35$ to 1.69 ) (Analysis 1.7).

\section{Ipsilateral stroke (fatal and non-fatal, ischaemic and haemorrhagic)}

During surgery, all strokes that occurred during surgery were ipsilateral. The risk of ipsilateral stroke in both groups combined was 2.4 per 100 operations (18/737). Again, the best- and worstcase analyses gave qualitatively different results (OR 0.42 and 1.32 respectively), although neither was significant (best case: Analysis 1.8; worst case: Analysis 1.9) .

During surgery or within 30 days of surgery, the risk of ipsilateral stroke was 3.0 per 100 operations (22/737). There was a trend for fewer strokes in the shunted group in both the best- and worstcase analyses (OR 0.41 and 0.88 respectively) but again, the small number of events makes these results difficult to interpret (best case: Analysis 1.10; worst case: Analysis 1.11).

\section{Death or stroke within 30 days of surgery}

The risk of death or stroke in patients (with unilateral or bilateral identical operations only) was $4.9 \%(32 / 655)$ overall. The bestand worst-case analyses showed non-significant trends favouring shunting (OR 0.62 and 0.81 respectively) but once again, the confidence intervals were wide (best case: Analysis 1.12; worst case: Analysis 1.13).

\section{Other complications}

The risks of wound haemorrhage or arterial rupture $(0.3 \%)$ and wound infection $(0.2 \%)$ were too small to reliably detect any difference between the two treatment groups. Nerve palsies were only recorded in one trial (Gumerlock 1988) and no significant difference was found between the two groups (3.6\% risk overall) (Analysis 1.14; Analysis 1.15; Analysis 1.16).

\section{Cognitive function}

In the most recent trial, all participants underwent neuropsychological testing before the operation and three weeks after surgery (Palombo 2007). This study did not observe any statistical difference between the two groups before or after carotid surgery with regard to neuropsychological testing.

\section{Comparison of routine shunting versus selective shunting}

A single randomised controlled trial compared the results of routine shunting versus selective shunting based on stump pressure (AbuRahma 2010).There were no significant differences in clinical outcome between routine shunting and selective shunting. The perioperative stroke rate was $0 \%$ for routine shunting versus $2 \%$ for selective shunting (one major and one minor stroke, both related to carotid thrombosis) No participants died perioperatively. Combined perioperative TIA and stroke rates were $2 \%$ in routine shunting versus $2.9 \%$ in selective shunting. This study concluded that there were no significant differences between routine shunting and selective shunting.

\section{Comparison of monitoring methods in selective shunting \\ EEG plus carotid stump pressure assessment versus stump pressure assessment alone}

In Fletcher 1988 the risks of stroke or death per participant were not available from the published report. Five participants had a stroke within 24 hours of surgery (a risk of 3.5 per 100 operations.) There was no significant difference between combined EEG monitoring and carotid pressure assessment and carotid pressure assessment alone. In the combined monitoring group, two of the three strokes occurred in participants with abnormal EEGs who were not shunted because the carotid artery pressure was greater than $50 \mathrm{mmHg}$. The other stroke occurred in a participant with a normal EEG and a carotid pressure of greater than $55 \mathrm{mmHg}$. In the group with carotid stump pressure assessment alone, the two strokes occurred in participants with pressures greater than $55 \mathrm{mmHg}$. The risk of wound haemorrhage was too low $(2.8 \%)$ to reliably detect any difference between the treatment groups. The risk of nerve palsies was higher (7.7\%) but there was no apparent difference between the two groups. Combined monitoring results in about $50 \%$ fewer shunts being inserted (12 per 100 operations) than carotid artery pressure assessment alone ( 26 per 100 operations), but the numbers were small and so are not reliable.

\section{The use of an intraoperative algorithm based on cerebral oximetry with near-infrared spectroscopy (NIRS) monitoring}

Zogogiannis 2011 evaluated whether the use of an intraoperative algorithm based on cerebral oximetry with NIRS monitoring could help in the intraoperative decision for shunt placement, in people undergoing carotid endarterectomy. Two hundred and fifty-three participants who underwent carotid endarterectomy under general anaesthesia were randomly allocated to Group A (83 participants) using NIRS monitoring and the suggested algorithm, Group B (84 participants) using NIRS monitoring without the algorithm and Group C (86 participants) who served as controls. Shunt placement criterion for Groups A and B was a 20\% drop in ipsilateral regional saturation from the baseline value recorded before surgery. The rate of shunting was $27.7 \%$ in group A, $59.5 \%$ in group B and $100 \%$ in group C. Regarding the rate of postoperative neurologic deficits, no significant difference was found between the three groups. This study concluded that the use of a specific algorithm based on NIRS monitoring, in people undergoing carotid endarterectomy, may reduce the rate for shunt placement. However, no significant effect of the reduced rate of shunting on the rate of neurological deficit was found.

\section{DISCUSSION}

Since the previous publication of this review there have been several new studies reporting the outcome of routine versus selective shunting in people undergoing carotid endarterectomy. However, most of these have been retrospective studies comparing the outcome of participants operated before and after a change in policy of shunt use (Bond 2002; Goodney 2012; Nguyen 2005; Woodworth 2007). Only two trials met the criteria for inclusion in this review (AbuRahma 2010; Zogogiannis 2011).

Of the six included trials, we identified three trials that compared routine shunting with no shunting (Gumerlock 1988; Palombo 2007; Sandmann 1993); only these three trials could be included in the meta-analysis. Two trials compared different monitoring methods in selective shunting (Fletcher 1988; Zogogiannis 2011),

Routine or selective carotid artery shunting for carotid endarterectomy (and different methods of monitoring in selective shunting) 
and one trial compared routine shunting with selective shunting (AbuRahma 2010). This trial showed no significant differences between routine shunting and selective shunting; however, too few outcomes, especially strokes, between the two groups. More trials are needed.

\section{Routine shunting versus no shunting}

\section{Summary of main results}

The data from RCTs on the use of routine shunting were limited. There were promising but non-significant trends favouring a reduction in stroke-related deaths within 30 days of surgery with routine shunting.

\section{Overall completeness and applicability of evidence}

These analyses were based on very small numbers of outcome events. A large multicentre randomised trial is required to assess whether shunting reduces the risk of perioperative and longterm death and stroke. Even a modest $25 \%$ reduction in the relative risk of perioperative stroke or death would result in approximately 15 fewer strokes and deaths per 1000 people undergoing endarterectomy. However, detecting this reliably $(80 \%$ power, 5\% significance level) would require between 3000 and 5000 participants. The duration of follow-up in the included trials was very short. The main aim of shunting is to reduce the risk of perioperative stroke but it could possibly be associated with an increased risk of restenosis and late recurrent stroke. This risk was not assessed in the included trials.

There were significant problems with the quality of the randomised trials. The method used for allocation concealment was inadequately reported in most of the included studies. The duration of follow-up was short in all included studies. It was also unclear in most of the studies whether the outcomes had been assessed blind to treatment allocation. It is well known that studies that have neurologists as assessors are associated with higher stroke and death rates (Rerkasem 2009; Rothwell 1996). Only two studies reported that they had independent assessors (psychologists, neurologists) (Palombo 2007; Sandmann 1993). Five of the trials reported complete outcome data.

\section{Potential biases in the review process}

There were several potential biases such as many cross-overs, imbalance in baseline characteristics and unavailable data for important baseline characteristics. These reduced the reliability of these results.

\section{Agreements and disagreements with other studies or reviews}

Our results showed that there were promising but non-significant trends favouring a reduction in both deaths and strokes within 30 days of surgery with the routine shunting policy. Opponents injuries, embolisation, and difficulty in visualising the endpoint of endarterectomy, and that there might be a reduced incidence of stroke due to technical mistakes in patients who are not shunted (Halsey 1992). However, accurate data on these risks appear limited and anecdotal. In contrast, many studies reported that routine outcomes were reported to detect any difference in the number of

\section{Quality of the evidence} of this policy argue that insertion of a shunt can cause intimal

shunting by experienced surgeons results in a low rate of shuntinduced problems, and a low rate of stroke and death, and is a cost-effective procedure (Hamdan 1999; Hertzer 1997). Routine shunting avoids the need for test clamping of the common carotid artery (awake testing), which alone can cause embolic stroke. Also, routine shunting obviates the need to intubate urgently, which may force an attempt to place the shunt under less than ideal conditions, possibly raising the risk of technical errors.

\section{Selective shunting versus no shunting}

There are no data currently available from RCTs regarding the benefits (or hazards) of selective shunting versus no shunting.

\section{Comparison of different methods of monitoring in selective shunting}

Again, the data from randomised trials on which method should be used to select patients for selective shunting were very limited. We only identified two trials. The first trial (131 patients) compared the use of EEG monitoring combined with an assessment of the carotid stump back pressure with carotid back pressure assessment alone (Fletcher 1988). This study was small and did not report details of randomisation, blinding of outcome assessment and the numbers of participants in each group. Too few outcomes were reported to detect any difference in the number of strokes in the group that received EEG and carotid pressure assessment compared with the group that received carotid pressure assessment alone. However, from this limited data EEG monitoring did appear more sensitive to cerebral ischaemia than carotid stump pressure: two strokes occurred during the operation in participants who had EEG changes but whose carotid stump pressure remained greater than $50 \mathrm{mmHg}$, whilst no participants had reduced pressure without EEG changes. Combined EEG and pressure monitoring may reduce the number of shunts inserted but it is difficult to interpret these data without reliable evidence that this method of monitoring does not increase the risk of stroke. In addition, if EEG monitoring is not associated with fewer strokes, the costs of extra EEG monitoring may outweigh the costs saved by inserting fewer shunts.

The second trial assessed whether the use of an intraoperative algorithm based on cerebral oximetry with NIRS monitoring could help in the intraoperative decision for shunt placement, in people undergoing carotid endarterectomy (253 participants) (Zogogiannis 2011). Two hundred and fifty-three participants, who underwent CEA under general anaesthesia, were randomly allocated to Group A using NIRS monitoring and the suggested algorithm, Group B using NIRS monitoring without the algorithm and Group $C$ who served as controls. This study was small and did not report details of randomisation, allocation concealment, blinding of the participants and personnel as well as outcome assessment. Shunt placement criterion for Group A and B was a $20 \%$ drop in ipsilateral regional saturation from the baseline value recorded before surgery. The rate of shunting was $27.7 \%$ in group A, $59.5 \%$ in group $B$ and $100 \%$ in group C. For the rate of postoperative neurologic deficits, no significant difference was found between the three groups. However, too few outcomes (13 participants) were reported to detect any difference in the number of strokes in each group.

There are many other methods of monitoring for cerebral ischaemia that may be more sensitive than EEG, carotid pressure monitoring and NIRS but these have not been subjected to assessment in RCTs. The key question is not whether these methods

Routine or selective carotid artery shunting for carotid endarterectomy (and different methods of monitoring in selective shunting) 10 
can reliably detect cerebral ischaemia but whether shunting in these people results in lower perioperative morbidity and case fatality.

\section{AUTHORS' CONCLUSIONS}

\section{Implications for practice}

There is still insufficient evidence from randomised controlled trials to support the use of routine shunting in carotid endarterectomy, although a clinically important benefit from routine shunting cannot be excluded. There is no reliable evidence at present to support the use of selective shunting. In those who wish to use selective shunting in people under general anaesthetic, there is again little evidence to support the use of one form of monitoring over another. Much more data are required to prove this.

\section{Implications for research}

A large multicentre randomised trial is required to assess whether shunting reduces the risk of perioperative and longterm death and stroke. Even a modest $25 \%$ reduction in the relative risk of perioperative stroke or death would result in approximately 15 fewer strokes and deaths per 1000 people undergoing endarterectomy. However, to detect this reliably $(80 \%$ power, $5 \%$ significance level) would require between 3000 and 5000 participants. Two policies could be considered: routine shunting for all people undergoing carotid endarterectomy or selective shunting in those at high risk of intraoperative cerebral ischaemia. The trial would have to be truly randomised, have long-term follow-up (several years) and have blinded outcome assessment preferably by neurologists. Patients should be stratified by age, sex, degree of ipsilateral and contralateral internal carotid stenosis, the experience of the surgeon, the use of patching and, in selective shunting, the method of monitoring of cerebral ischaemia.

As regards the method of monitoring in selective shunting, until the efficacy of shunting has been demonstrated, further trials of the method of monitoring are probably not merited. However, a systematic review of the sensitivity and specificity of the various methods of monitoring for cerebral ischaemia would be worthwhile to identify the best method of monitoring to be used in any trial of selective shunting (Irwig 1994).

\section{ACKNOWLEDGEMENTS}

We would like to thank: Hazel Fraser for providing us with references to relevant trials from the Cochrane Stroke Group's Trials Register; Brenda Thomas for helping with search strategy; Professor Peter Sandercock, Dr Eivind Berge and Devi Prasad Mohapatra for commenting on the manuscript; Mr Richard Bond and Professor Peter Rothwell for their contribution to previous versions of this review. Professor Kittipan Rerkasem was funded by The Thailand Research Fund (RSA5580008) and the Faculty of Medicine, Chiang Mai University.

\section{Ongoing trials}

If anyone is aware of any randomised trials that we have omitted please contact Professor Kittipan Rerkasem. 


\section{RE F E R E N C E S}

\section{References to studies included in this review}

AbuRahma 2010 \{published data only\}

Aburahma AF, Stone PA, Hass SM, Dean LS, Habib J, Keiffer T, et al. Prospective randomized trial of routine versus selective shunting in carotid endarterectomy based on stump pressure. Journal of Vascular Surgery 2010;51:1133-8.

Fletcher 1988 \{published data only\}

Fletcher JP, Morris JGL, Little JM, Kershaw LZ. EEG monitoring during carotid endarterectomy. Australian and New Zealand Journal of Surgery 1988;58:285-8.

\section{Gumerlock 1988 \{published and unpublished data\}}

Gumerlock MK, Neuwelt EA. Carotid endarterectomy: to shunt or not to shunt. Stroke 1988;19:1485-90.

\section{Palombo 2007 \{published data only\}}

Palombo D, Lucertini G, Mambrini S, Zettin M. Subtle cerebral damage after shunting vs non shunting during carotid endarterectomy. European Journal of Vascular and Endovascular Surgery 2007;34:546-51.

\section{Sandmann 1993 \{published and unpublished data\}} Sandmann W, Kolvenbach R, Willeke F. Risks and benefits of shunting in carotid endarterectomy. Stroke 1993;24:1098.

* Sandmann W, Willeke F, Kovenbach R, Benecke R, Godehardt E. To shunt or not to shunt: the definite answer with a randomized study. In: Veith FJ editor(s). Current Critical Problems in Vascular Surgery. Vol. 5, St Louis, Missouri: Quality Medical Publishing Inc, 1993:434-40.

Zogogiannis 2011 \{published data only\}

Zogogiannis ID, latrou CA, Lazarides MK, Vogiatzaki TD, Wachtel MS, Chatzigakis PK, et al. Evaluation of an intraoperative algorithm based on near-infrared refracted spectroscopy monitoring, in the intraoperative decision for shunt placement, in patients undergoing carotid endarterectomy.. Middle East Journal of Anesthesiology 2011;21:367-73.

\section{Additional references}

\section{ACAS 1995}

Executive Committee for the Asymptomatic Carotid Atherosclerosis study. Endarterectomy for asymptomatic carotid artery stenosis. JAMA 1995;273:1421-8.

\section{ACST 2004}

ACST Collaborative Group. Prevention of disabling and fatal strokes by successful carotid endarterectomy in patients without recent neurological symptoms: randomised controlled trial. MRC Asymptomatic Carotid Surgery Trial (ACST) Collaborative Group. Lancet 2004;363:1491-502.

\section{APT 1994}

Antiplatelet Trialists Collaboration. Collaborative overview of trials of antiplatelet therapy - I: Prevention of death, myocardial infarction, and stroke by prolonged antiplatelet therapy in various categories of patients. BMJ 1994;308:81-106.

\section{Benjamin 1993}

Benjamin ME, Silva MB, Watt C, McCaffrey MT, BurfordFoggs A, Flinn WR. Awake patient monitoring to determine the need for shunting during carotid endarterectomy. Surgery 1993;114:673-81.

\section{Bond 2002}

Bond R, Warlow C P, Naylor AR, Rothwell PM. Variation in surgical and anaesthetic technique and associations with operative risk in the European Carotid Surgery Trial: implications for trials of ancillary techniques. European Journal of Vascular and Endovascular Surgery 2002;23:117-26.

\section{Buche 1988}

Buche M, Grenier Y, Schoevaerdts JC, Jaumin P, Ponlot R, Chalant $\mathrm{CH}$. Comparative results after endarterectomy of internal carotid artery performed with or without a shunt. Journal of Cardiovascular Surgery 1988;29:428-31.

\section{Connolly 1977}

Connolly JE, Jack HM, Stemmer EA. Improved results with carotid endarterectomy. Annals of Surgery 1977;186:334-42.

\section{ECST 1991}

European Carotid Surgery Trialists Collaborative Group. MRC Carotid Surgery Trial: interim results for symptomatic patients with severe $(70-99 \%)$ or with mild $(0-29 \%)$ carotid stenosis. Lancet 1991;337:1235-43.

\section{Evans 1985}

Evans WE, Hayes JP, Waltke, EA, Vermilion BD. Optimal cerebra monitoring during carotid endarterectomy: neurologic response under local anaesthetic. Journal of Vascular Surgery 1985;2:775-7.

\section{Fode 1986}

Fode NC, Sundt TM, Robertson JT, Peerless SJ, Shields CB. Multicenter retrospective review of results and complications of carotid endarterectomy in 1981. Stroke 1986;17:370-5.

\section{Forssell 1995}

Forssell C, Kitzing P, Bergqvist D. Cranial nerve injuries after carotid surgery. A prospective study of 663 operations. European Journal of Vascular Surgery 1995;10:445-9.

\section{Girn 2008}

Girn HR, Dellagrammaticas D, Laughlan K, Gough MJ, for the GALA Trial Collaborators. Carotid endarterectomy: technical practices of surgeons participating in the GALA trial. European Journal of Vascular and Endovascular Surgery 2008;36:385-9.

\section{Goodney 2012}

Goodney PP, Wallaert JB, Scali ST, Stone DH, Patel V, Shaw P, et al. Impact of practice patterns in shunt use during carotid endarterectomy with contralateral carotid occlusion. Journal of vascular Surgery 2012;55:61-71.

Routine or selective carotid artery shunting for carotid endarterectomy (and different methods of monitoring in selective shunting) 


\section{Green 1985}

Green RM, Messick WJ, Ricotta JJ, Charlton MH, Satran R, McBride MM, et al. Benefits, shortcomings, and costs of EEG monitoring. Annals of Surgery 1985;201:785-92.

\section{Halsey 1992}

Halsey JH Jr. Risks and benefits of shunting in carotid endarterectomy. The International Transcranial Doppler Collaborators. Stroke 1992;23:1583-7.

\section{Hamdan 1999}

Hamdan AD, Pomposelli FB Jr, Gibbons GW, Campbell DR, LoGerfo FW. Perioperative strokes after 1001 consecutive carotid endarterectomy procedures without an electroencephalogram: incidence, mechanism, and recovery. Archives of Surgery 1999;134:412-5.

\section{Hertzer 1997}

Hertzer NR, O'Hara PJ, Mascha EJ, Krajewski LP, Sullivan TM, Beven EG. Early outcome assessment for 2228 consecutive carotid endarterectomy procedures: the Cleveland Clinic experience from 1989 to 1995. Journal of Vascular Surgery 1997;26:1-10.

\section{Higgins 2003}

Higgins JPT, Thompson SG, Deeks JJ, Altman DG. Measuring inconsistency in meta-analysis. BMJ 2003;327:557-60.

\section{Higgins 2011}

Higgins JPT, Green S (editors). Cochrane Handbook for Systematic Reviews of Interventions Version 5.1.0 [updated March 2011]. The Cochrane Collaboration, 2011. Available from www.cochrane-handbook.org.

\section{Irwig 1994}

Irwig L, Tosteson ANA, Gatsonis C, Lau J, Colditz G, Chalmers TC, et al. Guidelines for meta-analyses evaluating diagnostic tests. Annals of Internal Medicine 1994;120:667-76.

\section{Javid 1979}

Javid H, Julian OC, Dye WS, Hunter JA, Najafi H, Goldin MD, et al. Seventeen-year experience with routine shunting in carotid surgery. World Journal of Surgery 1979;3:167-77.

\section{Lewis 2008}

Lewis SC, Warlow CP, Bodenham AR, Colam B, Rothwell PM, Torgerson D, et al. General anaesthesia versus local anaesthesia for carotid surgery (GALA): a multicentre, randomised controlled trial. Lancet 2008;372:2132-42.

\section{NASCET 1991}

North American Symptomatic Carotid Endarterectomy Trial Collaborators. Beneficial effect of carotid endarterectomy in symptomatic patients with high-grade carotid stenosis. New England Journal of Medicine 1991;325:445-765.

\section{Nguyen 2005}

Nguyen TQ, Lind L, Harris EJ Jr. Selective shunting during carotid endarterectomy. Vascular 2005;13:23-7.

\section{Ott 1980}

Ott DA, Cooley DA, Chapa L, Coelho A. Carotid endarterectomy without temporary intraluminal shunt. Study of 309 consecutive operations. Annals of Surgery 1980;191:708-14.

\section{Ouriel 1987}

Ouriel K, Green RM. Clinical and technical factors influencing recurrent carotid stenosis and occlusion after endarterectomy. Journal of Vascular Surgery 1987;5:702-6.

\section{Prioleau 1977}

Prioleau WH, Aiken AF, Hairston P. Carotid endarterectomy. Neurologic complications as related to surgical techniques. Annals of Surgery 1977;185:678-83.

\section{Reddy 1987}

Reddy K, West M, Anderson B. Carotid endarterectomy without indwelling shunts and intraoperative electrophysiologic monitoring. Canadian Journal of Neurological Sciences 1987;14:131-5.

\section{Rerkasem 2009}

Rerkasem K, Rothwell PM. Temporal trends in the risks of stroke and death due to carotid endarterectomy for symptomatic carotid stenosis: an updated systematic review. European Journal of Vascular and Endovascular Surgery 2009;37:504-11.

\section{Rerkasem 2011}

Rerkasem K, Rothwell PM. Carotid endarterectomy for symptomatic carotid stenosis. Cochrane Database of Systematic Reviews 2011, Issue 4. [DOI: 10.1002/14651858.CD001081.pub2]

\section{RevMan 2012 [Computer program]}

The Nordic Cochrane Centre, The Cochrane Collaboration. Review Manager (RevMan). Version 5.2. Copenhagen: The Nordic Cochrane Centre, The Cochrane Collaboration, 2012.

\section{Ricotta 1983}

Ricotta JJ, Charlton MH, DeWeese JA. Determining criteria for shunt placement during carotid endarterectomy. EEG versus back pressure. Annals of Surgery 1983;198:642-5.

\section{Rothwell 1996}

Rothwell PM, Slattery J, Warlow CP. A systematic review of the risk of stroke and death due to endarterectomy for symptomatic carotid stenosis. Stroke 1996;27:260-5.

\section{Salvian 1997}

Salvian AJ, Taylor DC, Hsiang YN, Hildebrand HD, Litherland HK, Humer MF, et al. Selective shunting with EEG monitoring is safer than routine shunting for carotid endarterectomy. Cardiovascular Surgery 1997;5:481-5.

\section{Schulz 1995}

Schulz KF, Chalmers I, Hayes RJ, Altman DG. Empirical evidence of bias. Dimensions of methodological quality associated with estimates of treatment effects in controlled trials. JAMA 1995;273:408-12. 


\section{Schweiger 1988}

Schweiger H, Kamp H-D, Dinkel M. Somatosensory evoked potentials (SEP) during carotid endarterectomy - end of shunt debate?. In: Boccalon H editor(s). Angiology: Strategy for Diagnosis and Therapeutics. Paris: John Libbey Eurotext, 1988:353-5.

\section{Steiger 1989}

Steiger HJ, Schaffer L, Boll J, Liechti S. Results of microsurgical carotid endarterectomy. A prospective study with transcranial Doppler and EEG monitoring, and elective shunting. Acta Neurochirurgica 1989;100:31-8.

\section{Sundt 1986}

Sundt TM, Sharbrough FW, Marsh WR, Ebersold MJ, Piepgras DG, Messick JM. The risk-benefit ratio of intraoperative shunting during carotid endarterectomy. Annals of Surgery 1986;203:196-204.

\section{Thompson 1979}

Thompson JE. Complications of carotid endarterectomy and their prevention. World Journal of Surgery 1979;3:155-65.

\section{Vaniyapong 2013}

Vaniyapong T, Chongruksut W, Rerkasem K. Local versus general anaesthesia for carotid endarterectomy. Cochrane Database of Systematic Reviews 2013, Issue 12. [DOI: 10.1002/14651858.CD000126]

\section{Whittemore 1983}

Whittemore AD, Kaufman JL, Kohler TR, Mannick JA. Routine electroencephalographic (EEG) monitoring during carotid endarterectomy. Annals of Surgery 1983;197:707-13.

\section{CHARACTERISTICS OF STUDIES}

Characteristics of included studies [ordered by study ID]

\section{Wilkinson 1997}

Wilkinson JM, Rochester JR, Sivaguru A, Cameron IC, Fisher R, Beard JD. Middle cerebral artery blood velocity, embolization, and neurological outcome during carotid endarterectomy. European Journal of Vascular and Endovascular Surgery 1997;14:402.

\section{Woodworth 2007}

Woodworth GF, McGirt MJ, Than KD, Huang J, Perler BA, Tamargo RJ. Selective versus routine intraoperative shunting during carotid endarterectomy: a multivariate outcome analysis. Neurosurgery 2007;61:1170-6.

\section{References to other published versions of this review \\ Bond 2002a}

Bond R, Rerkasem K, Rothwell PM. Routine or selective carotid artery shunting for carotid endarterectomy (and different methods of monitoring in selective shunting). Cochrane Database of Systematic Reviews 2002, Issue 2. [DOI: 10.1002/14651858.CD000190]

\section{Rerkasem 2009a}

Rerkasem K, Rothwell PM. Routine or selective carotid artery shunting for carotid endarterectomy (and different methods of monitoring in selective shunting). Cochrane Database of Systematic Reviews 2009, Issue 4. [DOI: 10.1002/14651858.CD000190.pub2]

* Indicates the major publication for the study

AbuRahma 2010

$\begin{array}{ll}\text { Methods } & \text { Method of randomisation: unknown } \\ & \text { Concealment: sealed envelops that were opened just before surgery } \\ & \text { Not blind } \\ \text { Cross-overs: none (ITT analysis) } \\ \text { Exclusions during trial: none } \\ \text { Loss to follow-up: none }\end{array}$

Participants USA

200 participants, 200 operations

Routine shunting: 98 operations

Selective shunting: 102 operations

Age: 45 to 89 years, mean 68 years

Sex: $48 \%$ male, $52 \%$ female

Comparability: age, sex, vascular risk factors similar between 2 groups

More asymptomatic ipsilateral arteries in routine shunting group: $58 \%$ versus $53 \%$

Contralateral artery stenosis (mean \%) routine shunting group: $38 \%$; selective shunting group: $40 \%$

Interventions

Treatment: selective shunting group; shunt selected if systolic stump pressure $<40 \mathrm{mmHg}$

Control: routine shunting group

Routine or selective carotid artery shunting for carotid endarterectomy (and different methods of monitoring in selective shunting) 
AbuRahma 2010 (Continued)

All operations under general anaesthetic; unknown patching rate

\begin{tabular}{ll} 
Outcomes & $\begin{array}{l}\text { TIA, stroke, combined stroke/TIA, death, bleeding, myocardial infarction, congestive, heart failure, } \\
\text { asymptomatic carotid thrombosis, recurrent laryngeal injury, all complications, number of shunted } \\
\text { artery }\end{array}$ \\
\hline Notes & $\begin{array}{l}\text { Exclusion: none } \\
\text { Follow-up: } 30 \text { days }\end{array}$
\end{tabular}

\section{Risk of bias}

\begin{tabular}{|c|c|c|}
\hline Bias & Authors' judgement & Support for judgement \\
\hline $\begin{array}{l}\text { Random sequence genera- } \\
\text { tion (selection bias) }\end{array}$ & Low risk & Quote: "200 CEA patients were randomised into" \\
\hline $\begin{array}{l}\text { Allocation concealment } \\
\text { (selection bias) }\end{array}$ & Low risk & $\begin{array}{l}\text { Quote: "Randomization was done using sealed envelopes that were open just } \\
\text { before surgery" }\end{array}$ \\
\hline $\begin{array}{l}\text { Blinding of participants } \\
\text { and personnel (perfor- } \\
\text { mance bias) } \\
\text { All outcomes }\end{array}$ & High risk & Not reported \\
\hline $\begin{array}{l}\text { Blinding of outcome as- } \\
\text { sessment (detection bias) } \\
\text { All outcomes }\end{array}$ & High risk & Not reported \\
\hline $\begin{array}{l}\text { Incomplete outcome data } \\
\text { (attrition bias) } \\
\text { All outcomes }\end{array}$ & Low risk & No loss to follow-up \\
\hline $\begin{array}{l}\text { Selective reporting (re- } \\
\text { porting bias) }\end{array}$ & High risk & Study authors did not report prespecified outcome \\
\hline Other bias & High risk & Not reported \\
\hline
\end{tabular}

Fletcher 1988

$\begin{array}{ll}\text { Methods } & \text { Method of randomisation: unknown (artery or patient randomised?) } \\ & \text { Not blind } \\ \text { Cross-overs: none } & \text { Exclusions during trial: none } \\ \text { Loss to follow-up: none } & \\ \text { Australia } & 131 \text { participants, } 142 \text { operations } \\ \text { EEG/pressure monitoring: } 72 \text { operations } \\ \text { Pressure assessment alone: } 70 \text { operations } \\ \text { Age: } 36 \text { to } 70 \text { years, mean } 58 \text { years } \\ \text { Sex: } 70 \% \text { male, } 30 \% \text { female } \\ \text { Comparability: age, sex, vascular risk factors similar between } 2 \text { groups } \\ \text { More asymptomatic ipsilateral arteries in pressure group: } 1 \% \text { versus } 11 \% \\ \text { Contralateral artery stenosis unknown } \\ \text { Treatment: EEG monitoring and carotid stump back pressure assessment; shunt selected if ipsilateral } \\ \text { EEG change (loss of voltage/activity) within } 3 \text { minutes of clamping and back pressure <50 mmHg }\end{array}$

Routine or selective carotid artery shunting for carotid endarterectomy (and different methods of monitoring in selective shunting) 
Fletcher 1988 (Continued)

Control: carotid stump back pressure assessment alone; shunt selected if back pressure $<50 \mathrm{mmHg}$

All operations under general anaesthetic; unknown patching rate

\begin{tabular}{ll}
\hline Outcomes & $\begin{array}{l}\text { Death plus stroke-related death, any stroke (during the operation), ipsilateral stroke, haemorrhage } \\
\text { from operation site, nerve palsies, number of shunted artery }\end{array}$ \\
\hline Notes & Exclusion: none \\
& Follow-up: duration unknown
\end{tabular}

\section{Risk of bias}

\begin{tabular}{|c|c|c|}
\hline Bias & Authors' judgement & Support for judgement \\
\hline $\begin{array}{l}\text { Random sequence genera- } \\
\text { tion (selection bias) }\end{array}$ & High risk & Quote: "Randomization was dependent on availability of an EEG technician" \\
\hline $\begin{array}{l}\text { Allocation concealment } \\
\text { (selection bias) }\end{array}$ & High risk & Not reported \\
\hline $\begin{array}{l}\text { Blinding of participants } \\
\text { and personnel (perfor- } \\
\text { mance bias) } \\
\text { All outcomes }\end{array}$ & High risk & Not reported \\
\hline $\begin{array}{l}\text { Blinding of outcome as- } \\
\text { sessment (detection bias) } \\
\text { All outcomes }\end{array}$ & High risk & Not reported \\
\hline $\begin{array}{l}\text { Incomplete outcome data } \\
\text { (attrition bias) } \\
\text { All outcomes }\end{array}$ & Low risk & No missing data \\
\hline $\begin{array}{l}\text { Selective reporting (re- } \\
\text { porting bias) }\end{array}$ & High risk & Study authors did not report prespecified outcome \\
\hline Other bias & High risk & Not reported \\
\hline
\end{tabular}

Gumerlock 1988

$\begin{array}{ll}\text { Methods } & \text { Method of randomisation: odd/even hospital number (patient randomised) } \\ & \text { Not blind } \\ \text { Cross-overs: shunt: } 3 \text { patients not shunted (analysed in original group) } \\ \text { Exclusions during trial: none } \\ \text { Loss to follow-up: none }\end{array}$

Routine or selective carotid artery shunting for carotid endarterectomy (and different methods of monitoring in selective shunting) 
Gumerlock 1988 (Continued)

All operations done under general anaesthetic; no monitoring; primary closure

Outcomes Death plus stroke-related death, any stroke (during operation, within 24 hours and 30 days of operation), ipsilateral stroke, haemorrhage from operation site, infection at operation site, nerve palsy

\begin{tabular}{ll}
\hline Notes & Exclusions: none \\
& Follow-up: 30 days \\
\hline
\end{tabular}

\section{Risk of bias}

\begin{tabular}{|c|c|c|}
\hline Bias & Authors' judgement & Support for judgement \\
\hline $\begin{array}{l}\text { Random sequence genera- } \\
\text { tion (selection bias) }\end{array}$ & High risk & Not reported \\
\hline $\begin{array}{l}\text { Allocation concealment } \\
\text { (selection bias) }\end{array}$ & High risk & Not reported \\
\hline $\begin{array}{l}\text { Blinding of participants } \\
\text { and personnel (perfor- } \\
\text { mance bias) } \\
\text { All outcomes }\end{array}$ & High risk & Not reported \\
\hline $\begin{array}{l}\text { Blinding of outcome as- } \\
\text { sessment (detection bias) } \\
\text { All outcomes }\end{array}$ & High risk & Not reported \\
\hline $\begin{array}{l}\text { Incomplete outcome data } \\
\text { (attrition bias) } \\
\text { All outcomes }\end{array}$ & Low risk & No missing data \\
\hline $\begin{array}{l}\text { Selective reporting (re- } \\
\text { porting bias) }\end{array}$ & High risk & Study authors did not report prespecified outcome \\
\hline Other bias & High risk & $\begin{array}{l}\text { Quote: "All CEs were performed by either the attending neurosurgeon or by a } \\
\text { senior neurosurgical resident under direct supervision". No data showed the } \\
\text { percentage of operations done by residents in each arm. Obviously residents } \\
\text { had less experience than the attending physician, even though such opera- } \\
\text { tions were done under direct supervision. This might be a risk of bias, if there } \\
\text { was a significant proportion of residents as operators in } 1 \text { group }\end{array}$ \\
\hline
\end{tabular}

\section{Palombo 2007}

\begin{tabular}{ll}
\hline Methods & Randomisation was done by a random number generator using computational method \\
& Concealment: unclear \\
& Blind outcome assessment: unclear \\
& No cross-overs \\
& Exclusions during trial: unclear \\
& Loss to follow-up: unclear \\
\hline Participants & Italy \\
& 96 participants \\
& Shunt: 48 participants; no shunt: 48 participants \\
& Age: mean 71.45 years \\
& Sex: $67 \%$ male, $33 \%$ female \\
Comparability: age, sex, vascular risk factors, indication for operation, degree of ipsilateral/contralater- \\
al stenosis in each group not given
\end{tabular}

Routine or selective carotid artery shunting for carotid endarterectomy (and different methods of monitoring in selective shunting) 
Palombo 2007 (Continued)

Overall: all had $66 \%$ asymptomatic

\begin{tabular}{ll}
\hline Interventions & $\begin{array}{l}\text { Treatment: Pruitt-Inahara shunt } \\
\text { Control: no shunt (shunted if stump pressure }<50 \mathrm{mmHg} \text { ) } \\
\text { All operations done under general anaesthetic with stump pressure measurement } \\
\text { All operations done by eversion carotid endarterectomy technique }\end{array}$ \\
\hline Outcomes & $\begin{array}{l}\text { Death and stroke, cerebral CT scan, serum concentration of S100 protein, neuron specific enolase, in- } \\
\text { terleukin-6, neuropsychological test }\end{array}$ \\
\hline Notes & $\begin{array}{l}\text { Exclusions: contralateral severe carotid stenosis or carotid occlusion, right-side involvement, age } \\
\text { greater than } 80 \text { years, dementia, previous disabling stroke, brain tumour, neuroleptic therapy and Mini } \\
\text { Mental State Examination score < } 24 \text { points } \\
\text { Follow-up: unclear }\end{array}$
\end{tabular}

\section{Risk of bias}

\begin{tabular}{|c|c|c|}
\hline Bias & Authors' judgement & Support for judgement \\
\hline $\begin{array}{l}\text { Random sequence genera- } \\
\text { tion (selection bias) }\end{array}$ & Low risk & $\begin{array}{l}\text { Quote: "Randomisation was done by a random number generator using com- } \\
\text { putational method that was managed by a statistician." }\end{array}$ \\
\hline $\begin{array}{l}\text { Allocation concealment } \\
\text { (selection bias) }\end{array}$ & High risk & Not reported \\
\hline $\begin{array}{l}\text { Blinding of participants } \\
\text { and personnel (perfor- } \\
\text { mance bias) } \\
\text { All outcomes }\end{array}$ & High risk & Not reported \\
\hline $\begin{array}{l}\text { Blinding of outcome as- } \\
\text { sessment (detection bias) } \\
\text { All outcomes }\end{array}$ & Unclear risk & $\begin{array}{l}\text { Neuropsychological test was done by psychologists but author did not report } \\
\text { whether they knew the randomisation code }\end{array}$ \\
\hline $\begin{array}{l}\text { Incomplete outcome data } \\
\text { (attrition bias) } \\
\text { All outcomes }\end{array}$ & Low risk & No participants lost to follow-up \\
\hline $\begin{array}{l}\text { Selective reporting (re- } \\
\text { porting bias) }\end{array}$ & Low risk & Study authors reported all prespecified outcomes \\
\hline Other bias & High risk & Not reported \\
\hline
\end{tabular}

Sandmann 1993

Methods Method of randomisation: opaque, sequentially-numbered sealed envelopes (artery randomised)

Blind outcome assessment

Cross-overs: shunt: 35 participants not shunted; no shunt: 10 participants shunted (all participants

analysed in original group)

Exclusions during trial: none

Loss to follow-up: none

\begin{tabular}{ll}
\hline Participants & Germany \\
& 472 participants, 441 with unilateral operations \\
& Shunt: 250 operations \\
& No shunt: 253 operations \\
& Age: mean 64 years \\
\hline
\end{tabular}

Routine or selective carotid artery shunting for carotid endarterectomy (and different methods of monitoring in selective shunting) 
Sex: $70 \%$ male, $30 \%$ female

Comparability: age, sex, vascular risk factors, indication for operation, degree of ipsilateral/contralater-

al stenosis in each group not given

Overall: all had ipsilateral stenosis > 70\% (20\% asymptomatic); $20 \%$ had contralateral stenosis > $80 \%$

\begin{tabular}{ll}
\hline Interventions & $\begin{array}{l}\text { Treatment: Javid shunt } \\
\text { Control: no shunt (shunted if significant changes on monitoring) } \\
\text { All operations done under general anaesthetic with EEG/SEP monitoring; at end of operation plication, } \\
\text { resection, vein interposition was performed to achieve laminar flow on Doppler }\end{array}$ \\
\hline Outcomes & $\begin{array}{l}\text { Death plus stroke-related death, any stroke (during the operation and within } 30 \text { days), ipsilateral } \\
\text { stroke, haemorrhage from operation site, infection at operation site }\end{array}$ \\
\hline Notes & $\begin{array}{l}\text { Exclusions: bilateral simultaneous endarterectomies, simultaneous reconstruction of supra-aortic } \\
\text { branch and carotid bifurcation } \\
\text { Follow-up: } 30 \text { days }\end{array}$
\end{tabular}

\section{Risk of bias}

\begin{tabular}{|c|c|c|}
\hline Bias & Authors' judgement & Support for judgement \\
\hline $\begin{array}{l}\text { Random sequence genera- } \\
\text { tion (selection bias) }\end{array}$ & Low risk & $\begin{array}{l}\text { Quote: "the use of the intraluminal Javid shunt was prospectively randomised } \\
\text { in a continuous series of } 503 \text { CEs" }\end{array}$ \\
\hline $\begin{array}{l}\text { Allocation concealment } \\
\text { (selection bias) }\end{array}$ & High risk & Not reported \\
\hline $\begin{array}{l}\text { Blinding of participants } \\
\text { and personnel (perfor- } \\
\text { mance bias) } \\
\text { All outcomes }\end{array}$ & Low risk & $\begin{array}{l}\text { Based on unpublished data, a neurologist who was blind to treatment alloca- } \\
\text { tion assessed participants post-operatively }\end{array}$ \\
\hline $\begin{array}{l}\text { Blinding of outcome as- } \\
\text { sessment (detection bias) } \\
\text { All outcomes }\end{array}$ & Low risk & $\begin{array}{l}\text { Quote: "In } 503 \text { cases evaluated preoperatively and postoperatively by an inde- } \\
\text { pendent neurologist, the use of a Javid shunt was prospectively randomised." }\end{array}$ \\
\hline $\begin{array}{l}\text { Incomplete outcome data } \\
\text { (attrition bias) } \\
\text { All outcomes }\end{array}$ & Low risk & Based on unpublished data, there was no loss to follow-up in this study \\
\hline $\begin{array}{l}\text { Selective reporting (re- } \\
\text { porting bias) }\end{array}$ & High risk & Study authors did not report prespecified outcome \\
\hline Other bias & High risk & Not reported \\
\hline
\end{tabular}

\section{Zogogiannis 2011}

\begin{tabular}{ll}
\hline Methods & Method of randomisation: unknown \\
& $\begin{array}{l}\text { Not blind } \\
\text { Cross-overs: none } \\
\text { Exclusions during trial: none } \\
\text { Loss to follow-up: none }\end{array}$ \\
\hline Participants & Greece \\
& 253 participants, 253 operations \\
Group A: using cerebral oximetry with the suggested algorithm (83 operations)
\end{tabular}

Routine or selective carotid artery shunting for carotid endarterectomy (and different methods of monitoring in selective shunting) 
Group B: using cerebral oximetry without the suggested algorithm (84 operations)

Group C: control group - routine shunting (86 operations)

Age: 48 to 82 years, mean 68.6 years

Sex: $73 \%$ male, $27 \%$ female

Comparability: age, sex, BMI, vascular risk factors, coronary artery disease, haemodialysis similar be-

tween 2 groups

Asymptomatic ipsilateral arteries: 67.4\% (group A), 66.7\% (group B), 67.4 (group C)

Contralateral artery stenosis unknown

Treatment: Intervention group
Group A: using cerebral oximetry with the suggested algorithm
Group B: using cerebral oximetry without the suggested algorithm
These 2 groups, surgeon was notified when a $20 \%$ drop from the baseline was found
Group C control group - routine shunting
All operations under general anaesthetic; unknown patching rate

\begin{tabular}{ll}
\hline Outcomes & Number of shunted arteries, neurological deficit, cardiovascular ischaemia \\
\hline Notes & Exclusion: none \\
& Follow-up: duration unknown
\end{tabular}

\section{Risk of bias}

\begin{tabular}{|c|c|c|}
\hline Bias & Authors' judgement & Support for judgement \\
\hline $\begin{array}{l}\text { Random sequence genera- } \\
\text { tion (selection bias) }\end{array}$ & Low risk & $\begin{array}{l}\text { Quote: "This prospective, controlled, randomised study in two Greek institu- } \\
\text { tions" }\end{array}$ \\
\hline $\begin{array}{l}\text { Allocation concealment } \\
\text { (selection bias) }\end{array}$ & High risk & Not reported \\
\hline $\begin{array}{l}\text { Blinding of participants } \\
\text { and personnel (perfor- } \\
\text { mance bias) } \\
\text { All outcomes }\end{array}$ & High risk & Not reported \\
\hline $\begin{array}{l}\text { Blinding of outcome as- } \\
\text { sessment (detection bias) } \\
\text { All outcomes }\end{array}$ & High risk & Not reported \\
\hline $\begin{array}{l}\text { Incomplete outcome data } \\
\text { (attrition bias) } \\
\text { All outcomes }\end{array}$ & Low risk & No missing data \\
\hline $\begin{array}{l}\text { Selective reporting (re- } \\
\text { porting bias) }\end{array}$ & Low risk & Study authors reported all prespecified outcomes \\
\hline Other bias & High risk & Not reported \\
\hline
\end{tabular}

BMI: body mass index

CEA: carotid endarterectomy

CT: computerised tomography

EEG: electroencephalogram

Routine or selective carotid artery shunting for carotid endarterectomy (and different methods of monitoring in selective shunting) 
ITT: intention to treat

SEP: somatosensory evoked potential

TIA: transient ischaemic attack

DATA AND ANALYSES

Comparison 1. Shunting (routine or selective) versus no shunting

\begin{tabular}{|c|c|c|c|c|}
\hline Outcome or subgroup title & $\begin{array}{l}\text { No. of } \\
\text { studies }\end{array}$ & $\begin{array}{l}\text { No. of } \\
\text { partici- } \\
\text { pants }\end{array}$ & Statistical method & Effect size \\
\hline $\begin{array}{l}1 \text { Death from all causes within } 30 \\
\text { days of surgery }\end{array}$ & 3 & 655 & Peto Odds Ratio (Peto, Fixed, 95\% Cl) & $0.45[0.13,1.59]$ \\
\hline $\begin{array}{l}\text { 1.1 Routine shunting versus no } \\
\text { shunting }\end{array}$ & 3 & 655 & Peto Odds Ratio (Peto, Fixed, 95\% Cl) & $0.45[0.13,1.59]$ \\
\hline $\begin{array}{l}2 \text { Stroke-related death within } 30 \\
\text { days of surgery (best case) }\end{array}$ & 3 & 655 & Peto Odds Ratio (Peto, Fixed, 95\% Cl) & $0.13[0.02,0.96]$ \\
\hline $\begin{array}{l}2.1 \text { Routine shunting versus no } \\
\text { shunting }\end{array}$ & 3 & 655 & Peto Odds Ratio (Peto, Fixed, 95\% Cl) & $0.13[0.02,0.96]$ \\
\hline $\begin{array}{l}3 \text { Stroke-related death within } 30 \\
\text { days of surgery (worst case) }\end{array}$ & 3 & 655 & Peto Odds Ratio (Peto, Fixed, 95\% Cl) & $0.37[0.05,2.62]$ \\
\hline $\begin{array}{l}3.1 \text { Routine shunting versus no } \\
\text { shunting }\end{array}$ & 3 & 655 & Peto Odds Ratio (Peto, Fixed, 95\% Cl) & $0.37[0.05,2.62]$ \\
\hline $\begin{array}{l}4 \text { Any stroke during surgery (best } \\
\text { case) }\end{array}$ & 3 & 655 & Peto Odds Ratio (Peto, Fixed, $95 \% \mathrm{Cl}$ ) & $0.42[0.16,1.07]$ \\
\hline $\begin{array}{l}4.1 \text { Routine shunting versus no } \\
\text { shunting }\end{array}$ & 3 & 655 & Peto Odds Ratio (Peto, Fixed, 95\% Cl) & $0.42[0.16,1.07]$ \\
\hline $\begin{array}{l}5 \text { Any stroke during surgery } \\
\text { (worst case) }\end{array}$ & 3 & 655 & Peto Odds Ratio (Peto, Fixed, 95\% Cl) & $1.32[0.52,3.38]$ \\
\hline $\begin{array}{l}5.1 \text { Routine shunting versus no } \\
\text { shunting }\end{array}$ & 3 & 655 & Peto Odds Ratio (Peto, Fixed, 95\% Cl) & $1.32[0.52,3.38]$ \\
\hline $\begin{array}{l}6 \text { Any stroke within } 24 \text { hours of } \\
\text { surgery }\end{array}$ & 2 & 214 & Peto Odds Ratio (Peto, Fixed, 95\% Cl) & $0.15[0.03,0.78]$ \\
\hline $\begin{array}{l}6.1 \text { Routine shunting versus no } \\
\text { shunting }\end{array}$ & 2 & 214 & Peto Odds Ratio (Peto, Fixed, 95\% Cl) & $0.15[0.03,0.78]$ \\
\hline $\begin{array}{l}7 \text { Any stroke within } 30 \text { days of } \\
\text { surgery }\end{array}$ & 3 & 655 & Peto Odds Ratio (Peto, Fixed, 95\% Cl) & $0.77[0.35,1.69]$ \\
\hline $\begin{array}{l}7.1 \text { Routine shunting versus no } \\
\text { shunting }\end{array}$ & 3 & 655 & Peto Odds Ratio (Peto, Fixed, 95\% Cl) & $0.77[0.35,1.69]$ \\
\hline $\begin{array}{l}8 \text { Ipsilateral stroke during surgery } \\
\text { (best case) }\end{array}$ & 3 & 737 & Peto Odds Ratio (Peto, Fixed, $95 \% \mathrm{Cl}$ ) & $0.42[0.17,1.08]$ \\
\hline
\end{tabular}

Routine or selective carotid artery shunting for carotid endarterectomy (and different methods of monitoring in selective shunting) 


\begin{tabular}{|c|c|c|c|c|}
\hline Outcome or subgroup title & $\begin{array}{l}\text { No. of } \\
\text { studies }\end{array}$ & $\begin{array}{l}\text { No. of } \\
\text { partici- } \\
\text { pants }\end{array}$ & Statistical method & Effect size \\
\hline $\begin{array}{l}8.1 \text { Routine shunting versus no } \\
\text { shunting }\end{array}$ & 3 & 737 & Peto Odds Ratio (Peto, Fixed, 95\% Cl) & $0.42[0.17,1.08]$ \\
\hline $\begin{array}{l}9 \text { Ipsilateral stroke during surgery } \\
\text { (worst case) }\end{array}$ & 3 & 737 & Peto Odds Ratio (Peto, Fixed, 95\% Cl) & $1.32[0.52,3.37]$ \\
\hline $\begin{array}{l}9.1 \text { Routine shunting versus no } \\
\text { shunting }\end{array}$ & 3 & 737 & Peto Odds Ratio (Peto, Fixed, 95\% Cl) & $1.32[0.52,3.37]$ \\
\hline $\begin{array}{l}10 \text { Ipsilateral stroke within } 30 \\
\text { days of surgery (best case) }\end{array}$ & 3 & 737 & Peto Odds Ratio (Peto, Fixed, 95\% Cl) & $0.41[0.18,0.97]$ \\
\hline $\begin{array}{l}10.1 \text { Routine shunting versus no } \\
\text { shunting }\end{array}$ & 3 & 737 & Peto Odds Ratio (Peto, Fixed, 95\% Cl) & $0.41[0.18,0.97]$ \\
\hline $\begin{array}{l}11 \text { Ipsilateral stroke within } 30 \\
\text { days of surgery (worst case) }\end{array}$ & 3 & 737 & Peto Odds Ratio (Peto, Fixed, 95\% Cl) & $0.88[0.38,2.05]$ \\
\hline 11.1 Routine shunting & 3 & 737 & Peto Odds Ratio (Peto, Fixed, 95\% Cl) & $0.88[0.38,2.05]$ \\
\hline $\begin{array}{l}12 \text { Stroke or death within } 30 \text { days } \\
\text { of surgery (best case) }\end{array}$ & 3 & 655 & Peto Odds Ratio (Peto, Fixed, 95\% Cl) & $0.62[0.31,1.27]$ \\
\hline $\begin{array}{l}12.1 \text { Routine shunting versus no } \\
\text { shunting }\end{array}$ & 3 & 655 & Peto Odds Ratio (Peto, Fixed, 95\% Cl) & $0.62[0.31,1.27]$ \\
\hline $\begin{array}{l}13 \text { Stroke or death within } 30 \text { days } \\
\text { of surgery (worst case) }\end{array}$ & 3 & 655 & Peto Odds Ratio (Peto, Fixed, 95\% Cl) & $0.81[0.40,1.66]$ \\
\hline $\begin{array}{l}13.1 \text { Routine shunting versus no } \\
\text { shunting }\end{array}$ & 3 & 655 & Peto Odds Ratio (Peto, Fixed, 95\% Cl) & $0.81[0.40,1.66]$ \\
\hline $\begin{array}{l}14 \text { Haemorrhage from operation } \\
\text { site }\end{array}$ & 2 & 641 & Peto Odds Ratio (Peto, Fixed, 95\% Cl) & $1.19[0.07,19.47]$ \\
\hline $\begin{array}{l}14.1 \text { Routine shunting versus no } \\
\text { shunting }\end{array}$ & 2 & 641 & Peto Odds Ratio (Peto, Fixed, 95\% Cl) & $1.19[0.07,19.47]$ \\
\hline 15 Infection of operation site & 2 & 641 & Peto Odds Ratio (Peto, Fixed, 95\% Cl) & $0.16[0.00,8.12]$ \\
\hline $\begin{array}{l}15.1 \text { Routine shunting versus no } \\
\text { shunting }\end{array}$ & 2 & 641 & Peto Odds Ratio (Peto, Fixed, 95\% Cl) & $0.16[0.00,8.12]$ \\
\hline 16 Nerve palsy post-operatively & 1 & 138 & Peto Odds Ratio (Peto, Fixed, 95\% Cl) & $1.81[0.30,10.82]$ \\
\hline $\begin{array}{l}16.1 \text { Routine shunting versus no } \\
\text { shunting }\end{array}$ & 1 & 138 & Peto Odds Ratio (Peto, Fixed, 95\% Cl) & $1.81[0.30,10.82]$ \\
\hline
\end{tabular}


Analysis 1.1. Comparison 1 Shunting (routine or selective) versus no shunting, Outcome 1 Death from all causes within 30 days of surgery.

\begin{tabular}{|c|c|c|c|c|c|}
\hline Study or subgroup & $\begin{array}{c}\text { Shunt } \\
\mathrm{n} / \mathrm{N}\end{array}$ & $\begin{array}{c}\text { No shunt } \\
n / N\end{array}$ & $\begin{array}{c}\text { Peto Odds Ratio } \\
\text { Peto, Fixed, } 95 \% \mathrm{Cl}\end{array}$ & Weight & $\begin{array}{c}\text { Peto Odds Ratio } \\
\text { Peto, Fixed, } 95 \% \mathrm{Cl}\end{array}$ \\
\hline \multicolumn{6}{|c|}{ 1.1.1 Routine shunting versus no shunting } \\
\hline Gumerlock 1988 & $1 / 53$ & $0 / 65$ & & $10.07 \%$ & $9.27[0.18,476.64]$ \\
\hline Palombo 2007 & $0 / 48$ & $0 / 48$ & & & Not estimable \\
\hline Sandmann 1993 & $2 / 220$ & $7 / 221$ & - & $89.93 \%$ & $0.32[0.09,1.21]$ \\
\hline Subtotal $(95 \% \mathrm{Cl})$ & 321 & 334 & & $100 \%$ & $0.45[0.13,1.59]$ \\
\hline \multicolumn{6}{|c|}{ Heterogeneity: $\mathrm{Tau}^{2}=0 ; \mathrm{Chi}^{2}=2.5, \mathrm{df}=1(\mathrm{P}=0.11) ; \mathrm{I}^{2}=60.03 \%$} \\
\hline \multicolumn{6}{|c|}{ Test for overall effect: $Z=1.24(P=0.22)$} \\
\hline Total $(95 \% \mathrm{CI})$ & 321 & 334 & & $100 \%$ & $0.45[0.13,1.59]$ \\
\hline \multicolumn{6}{|c|}{ Total events: 3 (Shunt), 7 (No shunt) } \\
\hline \multicolumn{6}{|c|}{ Heterogeneity: $\operatorname{Tau}^{2}=0 ; \mathrm{Chi}^{2}=2.5, \mathrm{df}=1(\mathrm{P}=0.11) ; \mathrm{I}^{2}=60.03 \%$} \\
\hline
\end{tabular}

Analysis 1.2. Comparison 1 Shunting (routine or selective) versus no shunting, Outcome 2 Stroke-related death within 30 days of surgery (best case).

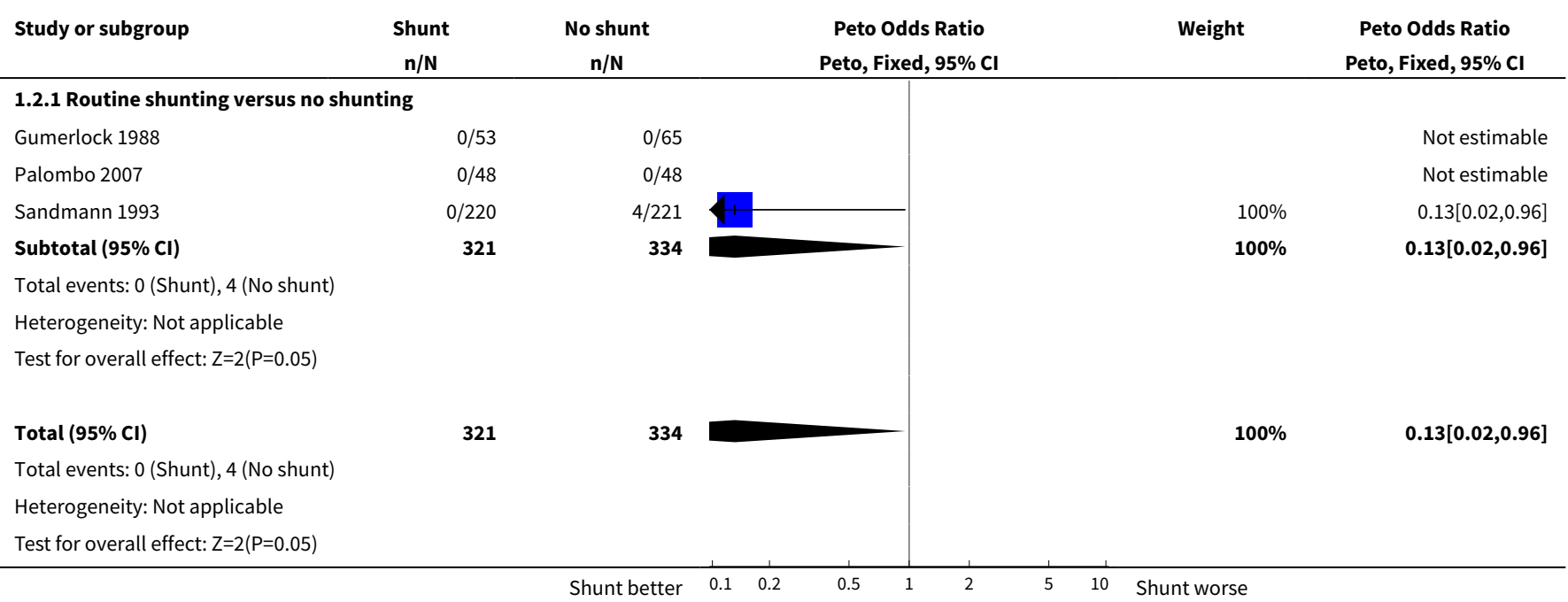

Analysis 1.3. Comparison 1 Shunting (routine or selective) versus no shunting, Outcome 3 Stroke-related death within $\mathbf{3 0}$ days of surgery (worst case).

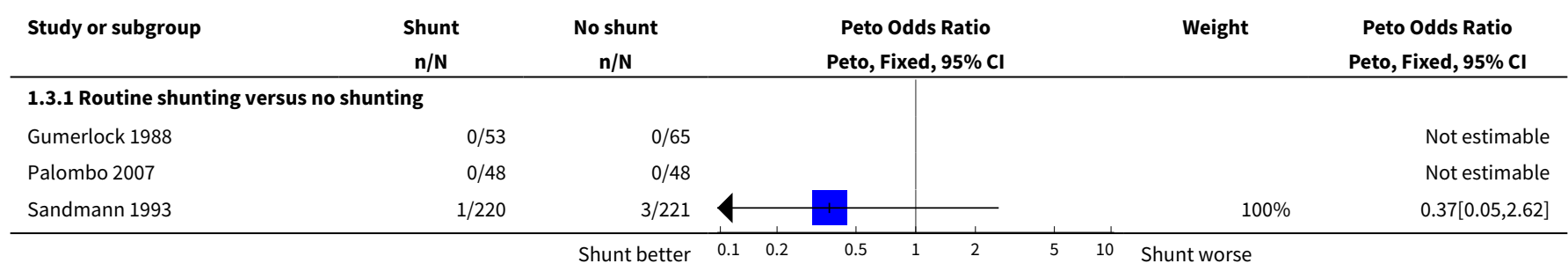

Routine or selective carotid artery shunting for carotid endarterectomy (and different methods of monitoring in selective shunting) 


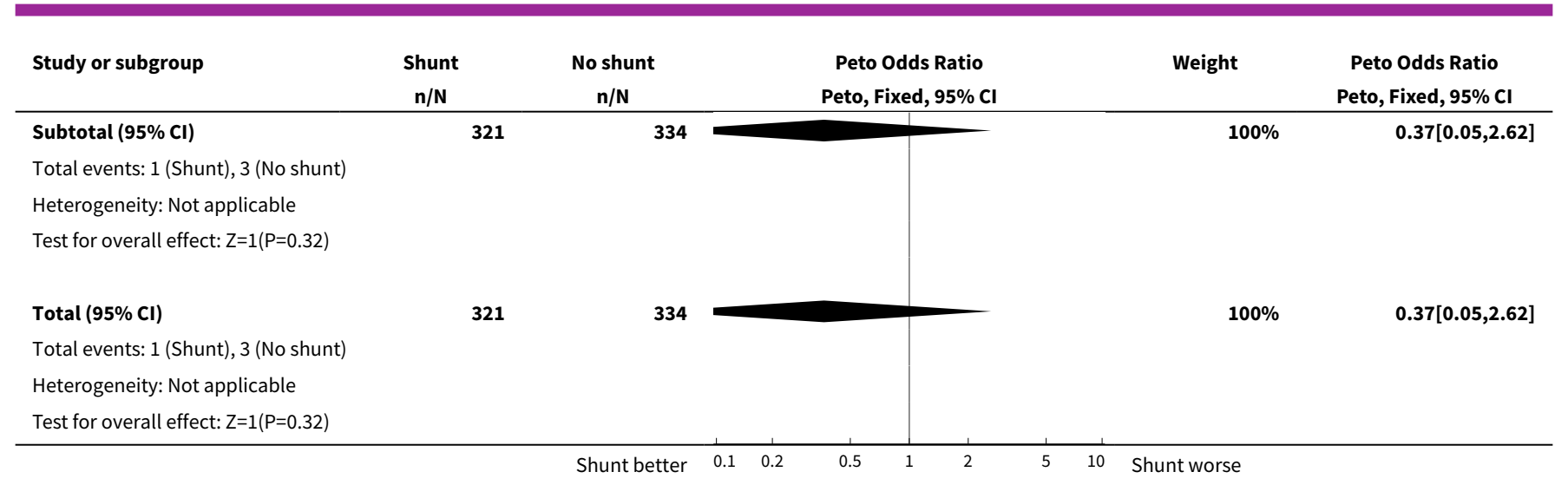

Analysis 1.4. Comparison 1 Shunting (routine or selective) versus no shunting, Outcome 4 Any stroke during surgery (best case).

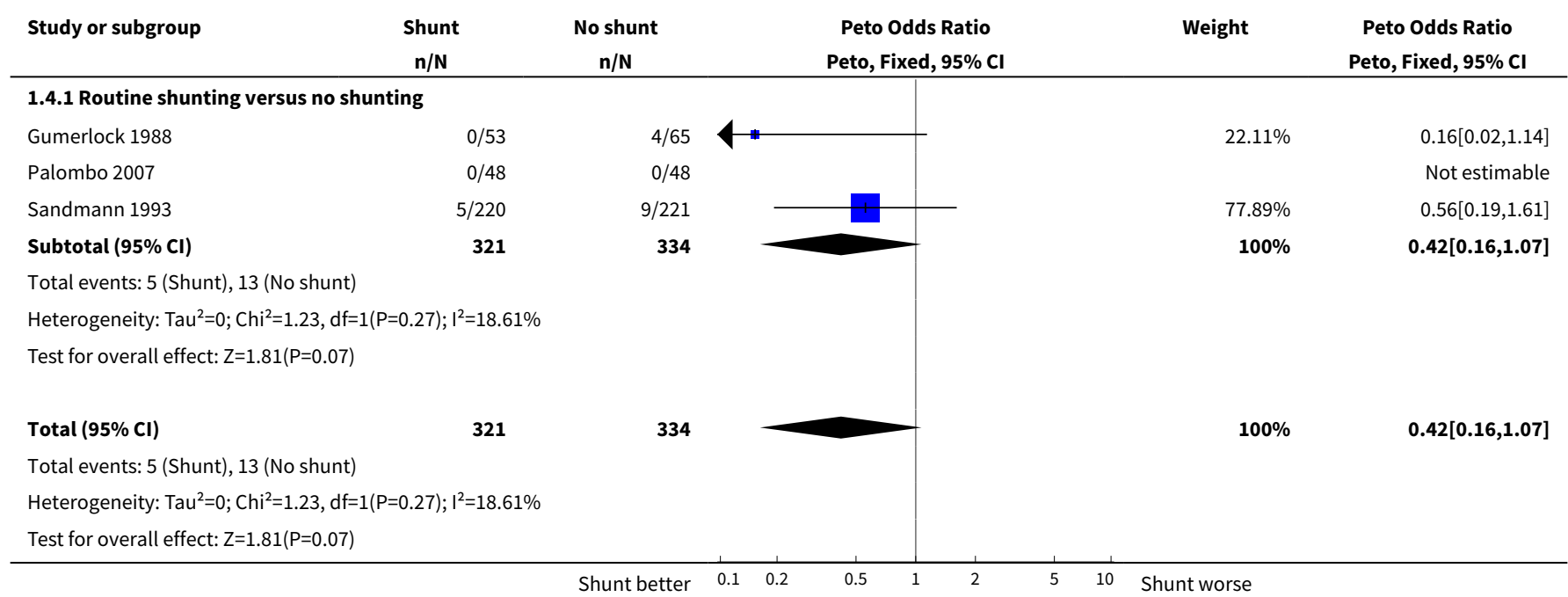

Analysis 1.5. Comparison 1 Shunting (routine or selective) versus no shunting, Outcome 5 Any stroke during surgery (worst case).

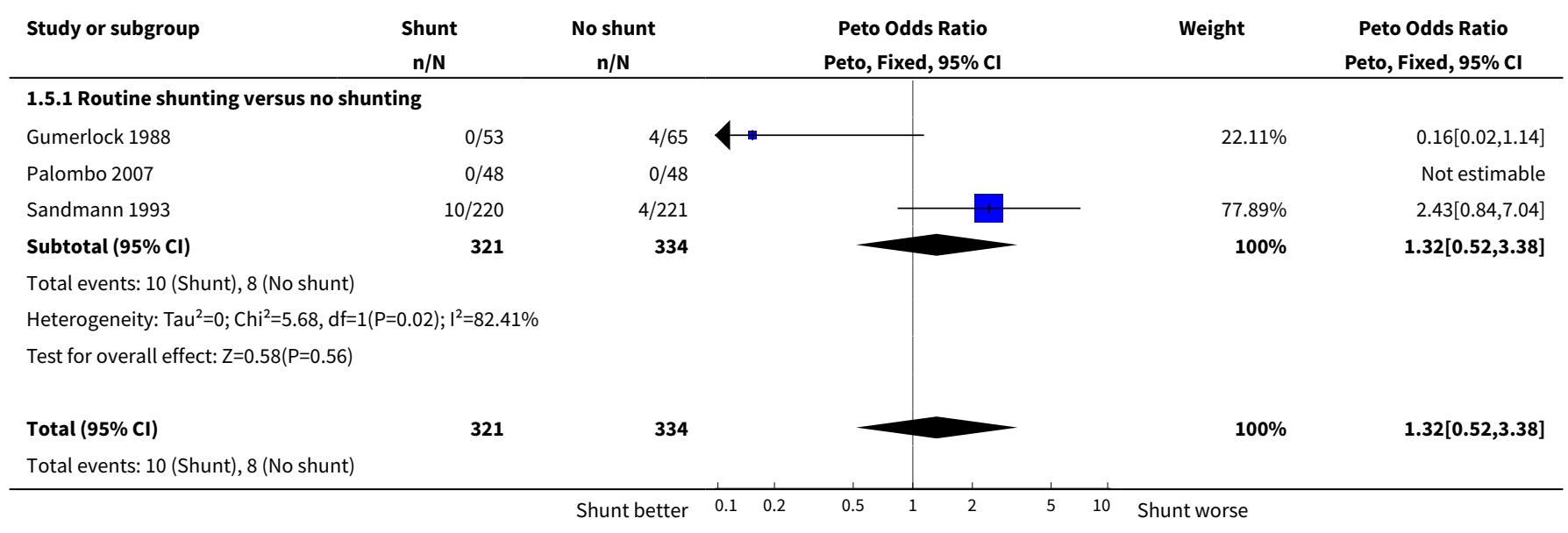




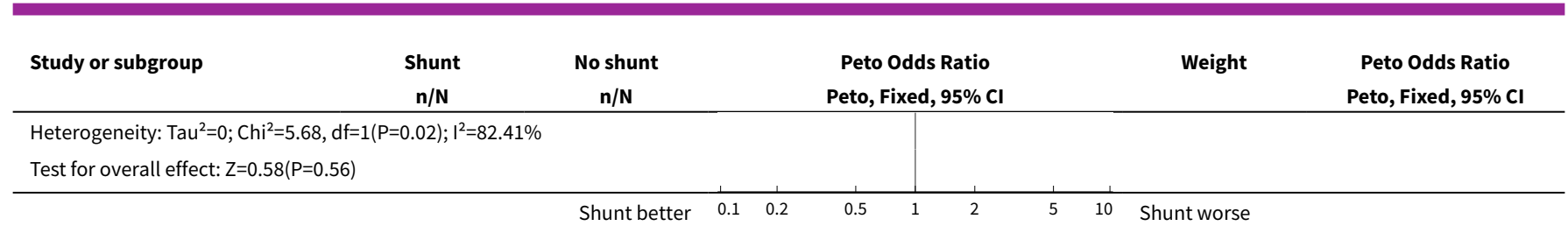

Analysis 1.6. Comparison 1 Shunting (routine or selective) versus no shunting, Outcome 6 Any stroke within 24 hours of surgery.

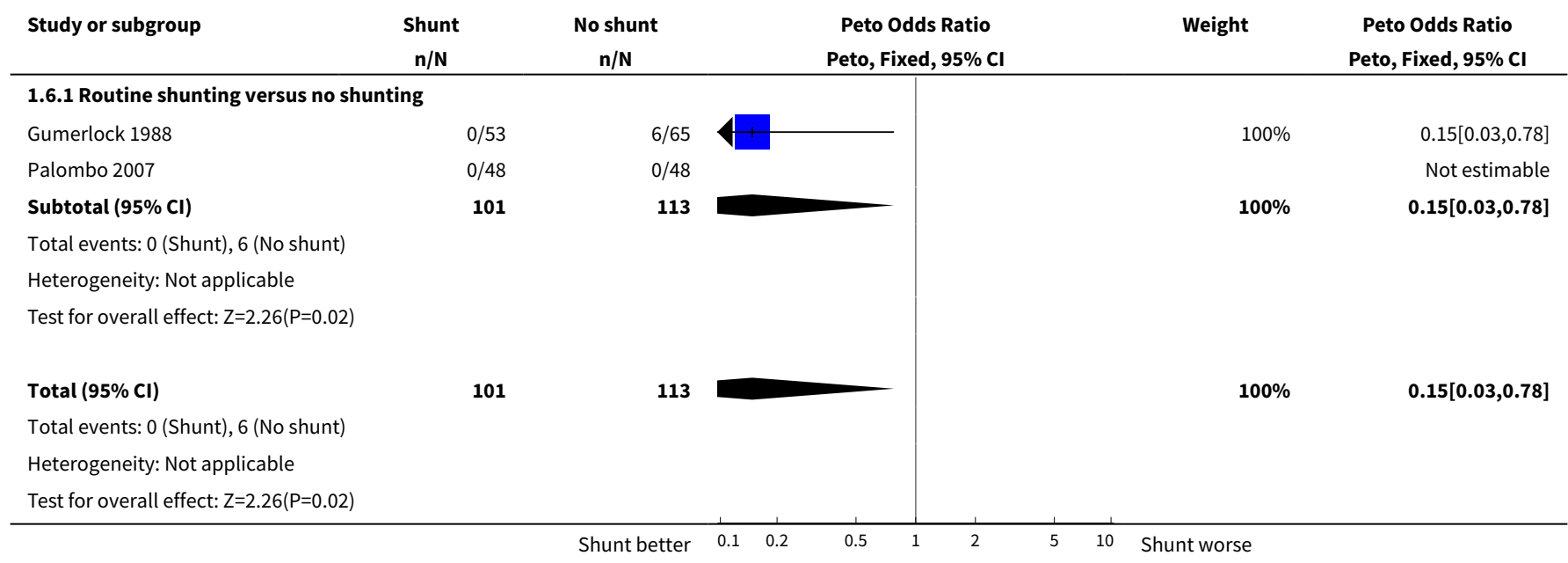

\section{Analysis 1.7. Comparison 1 Shunting (routine or selective) versus no shunting, Outcome 7 Any stroke within 30 days of surgery.}

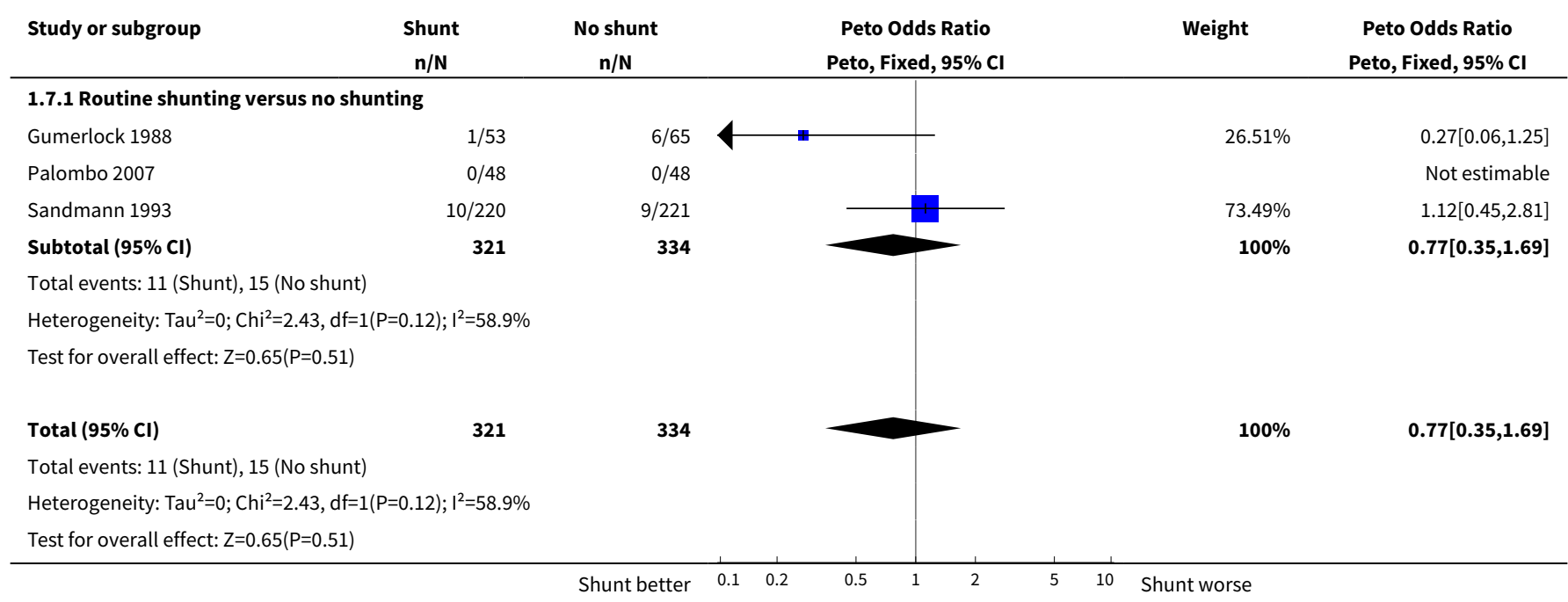

Routine or selective carotid artery shunting for carotid endarterectomy (and different methods of monitoring in selective shunting) 
Analysis 1.8. Comparison 1 Shunting (routine or selective) versus no shunting, Outcome 8 Ipsilateral stroke during surgery (best case).

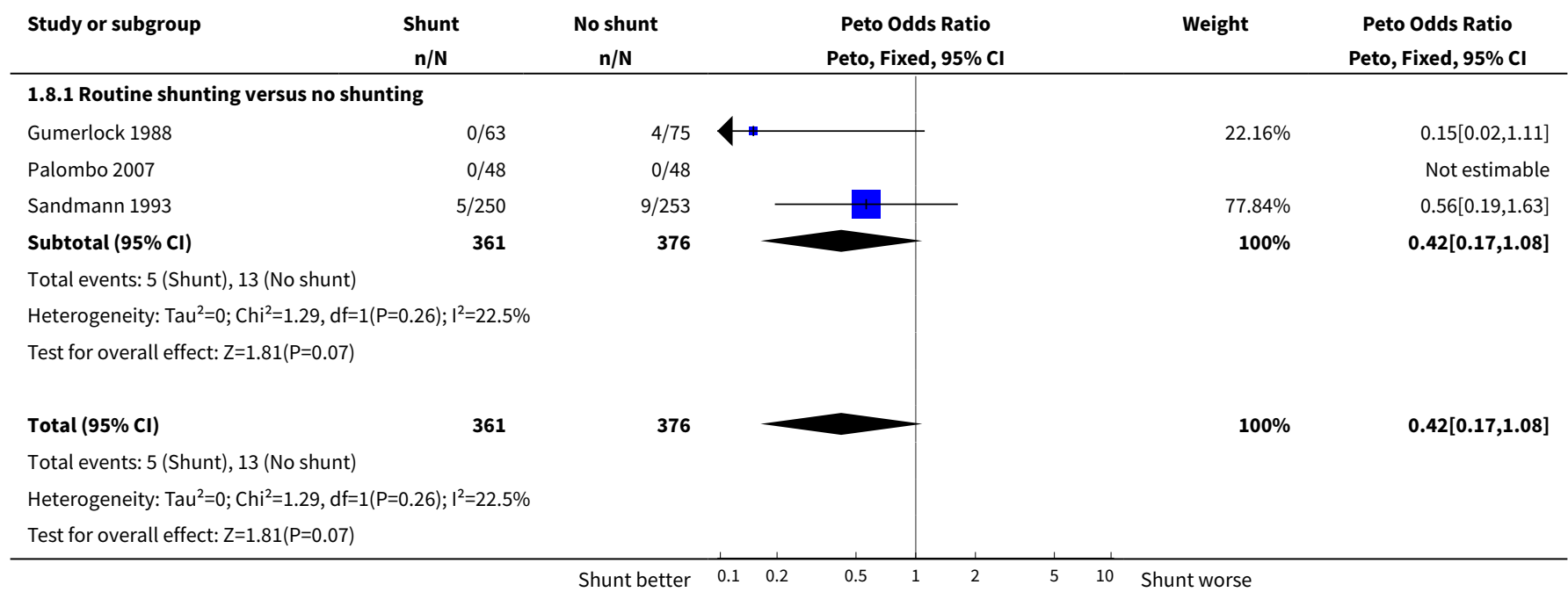

Analysis 1.9. Comparison 1 Shunting (routine or selective) versus no shunting, Outcome 9 Ipsilateral stroke during surgery (worst case).

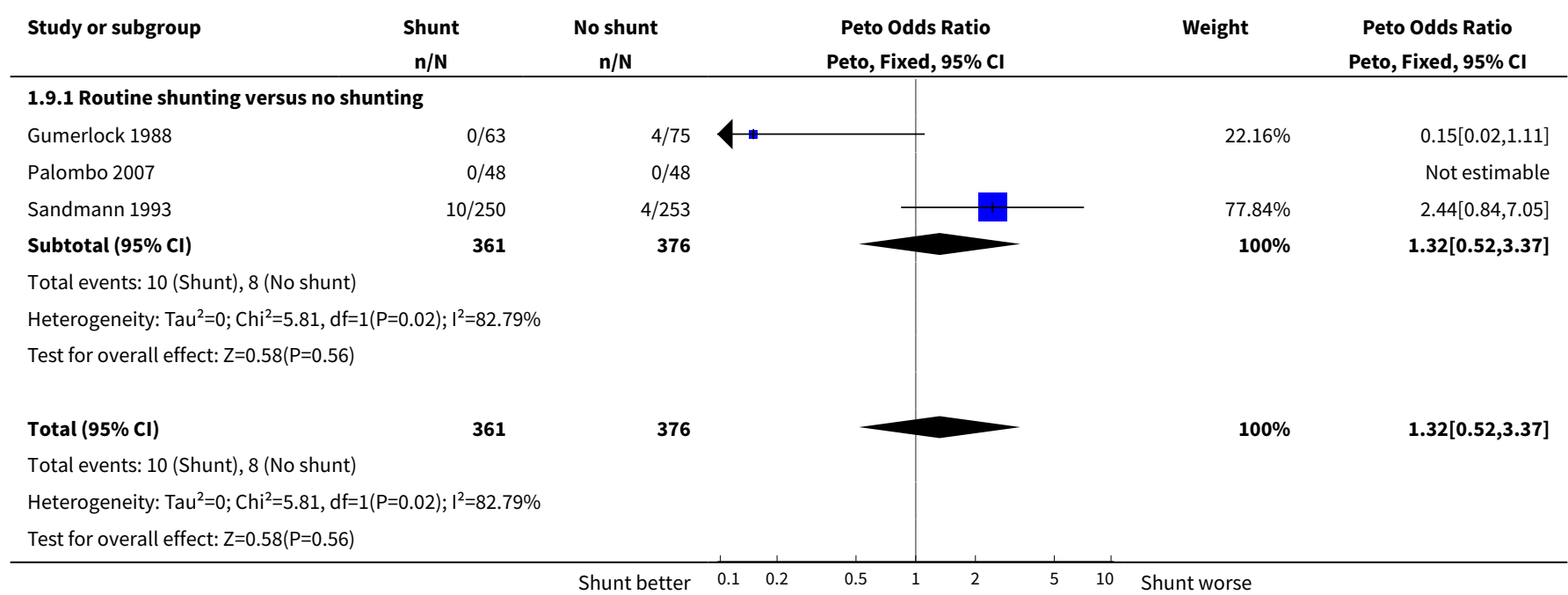

Analysis 1.10. Comparison 1 Shunting (routine or selective) versus no shunting, Outcome 10 Ipsilateral stroke within 30 days of surgery (best case).

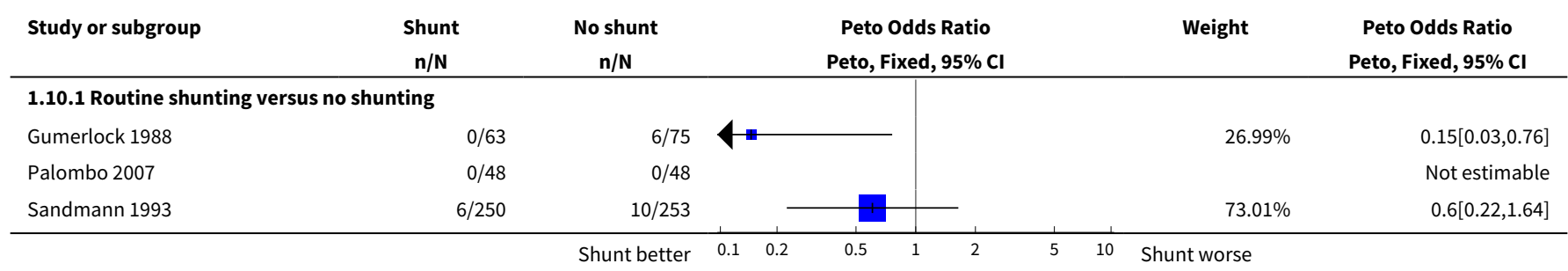




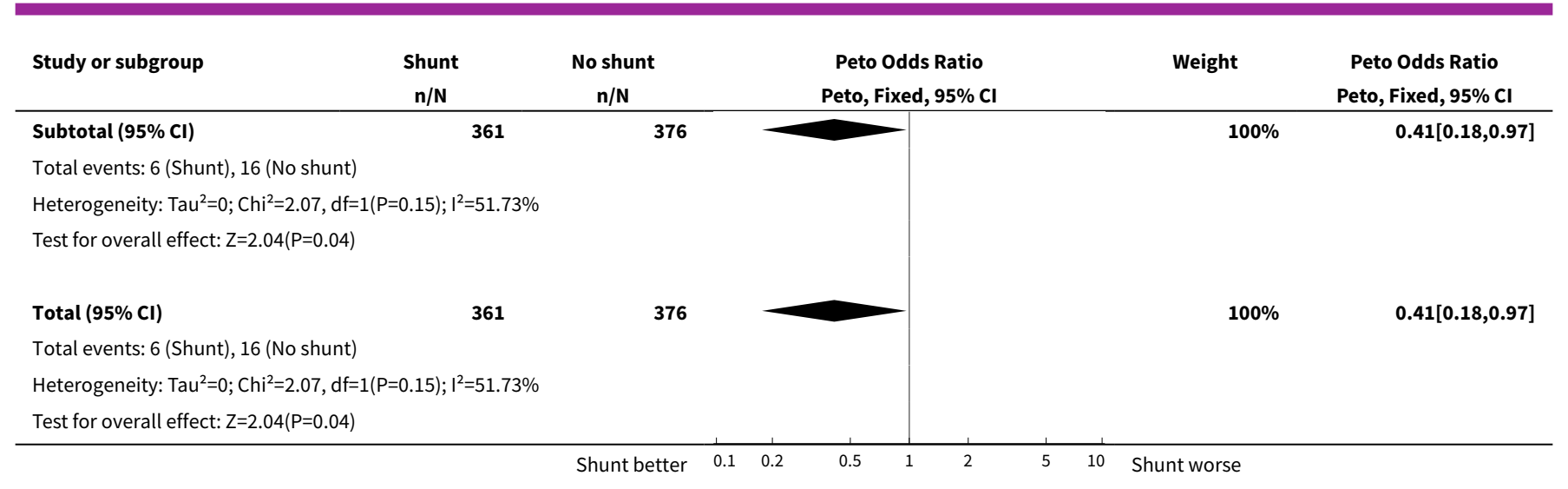

Analysis 1.11. Comparison 1 Shunting (routine or selective) versus no shunting, Outcome 11 Ipsilateral stroke within 30 days of surgery (worst case).

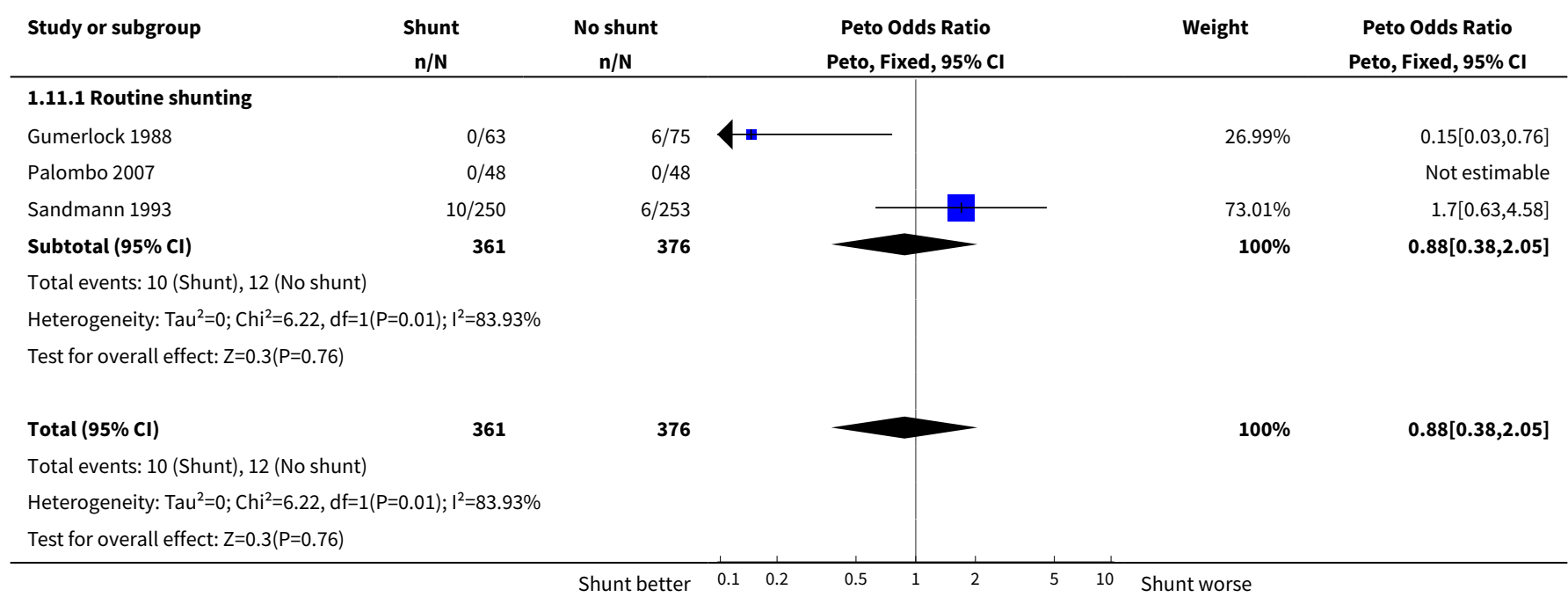

Analysis 1.12. Comparison 1 Shunting (routine or selective) versus no shunting, Outcome 12 Stroke or death within $\mathbf{3 0}$ days of surgery (best case).

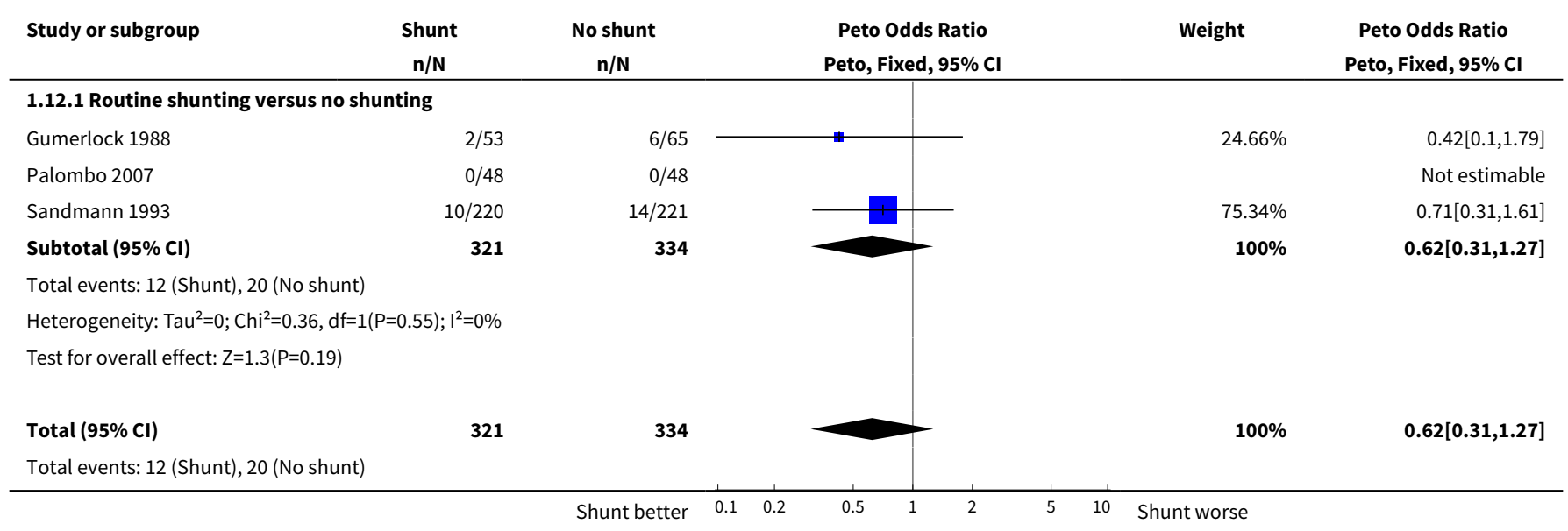




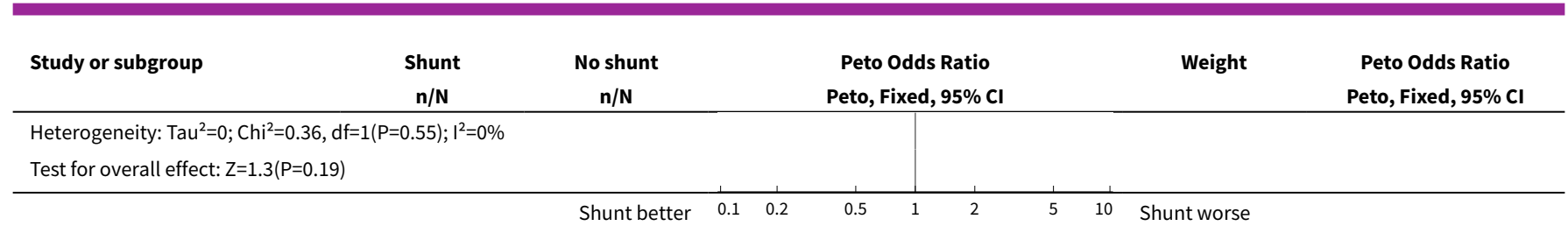

Analysis 1.13. Comparison 1 Shunting (routine or selective) versus no shunting, Outcome 13 Stroke or death within 30 days of surgery (worst case).

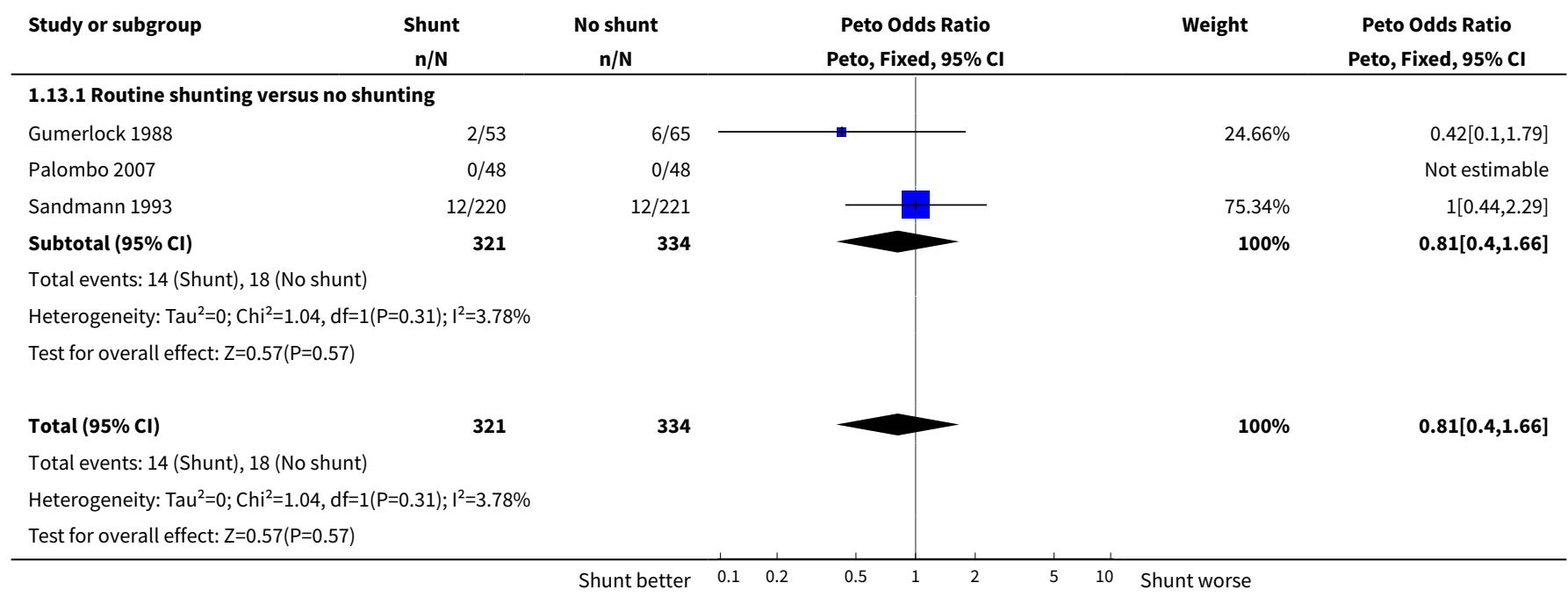

Analysis 1.14. Comparison 1 Shunting (routine or selective) versus no shunting, Outcome 14 Haemorrhage from operation site.

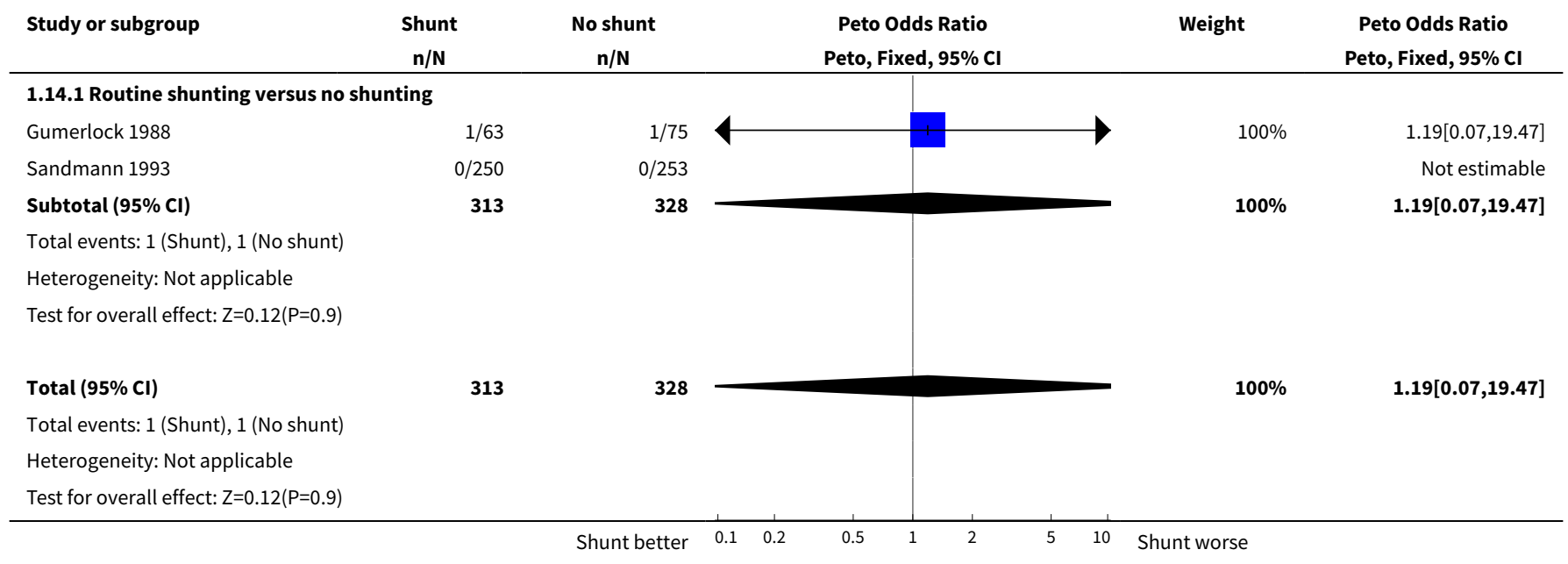

Routine or selective carotid artery shunting for carotid endarterectomy (and different methods of monitoring in selective shunting) 
Analysis 1.15. Comparison 1 Shunting (routine or selective) versus no shunting, Outcome 15 Infection of operation site.

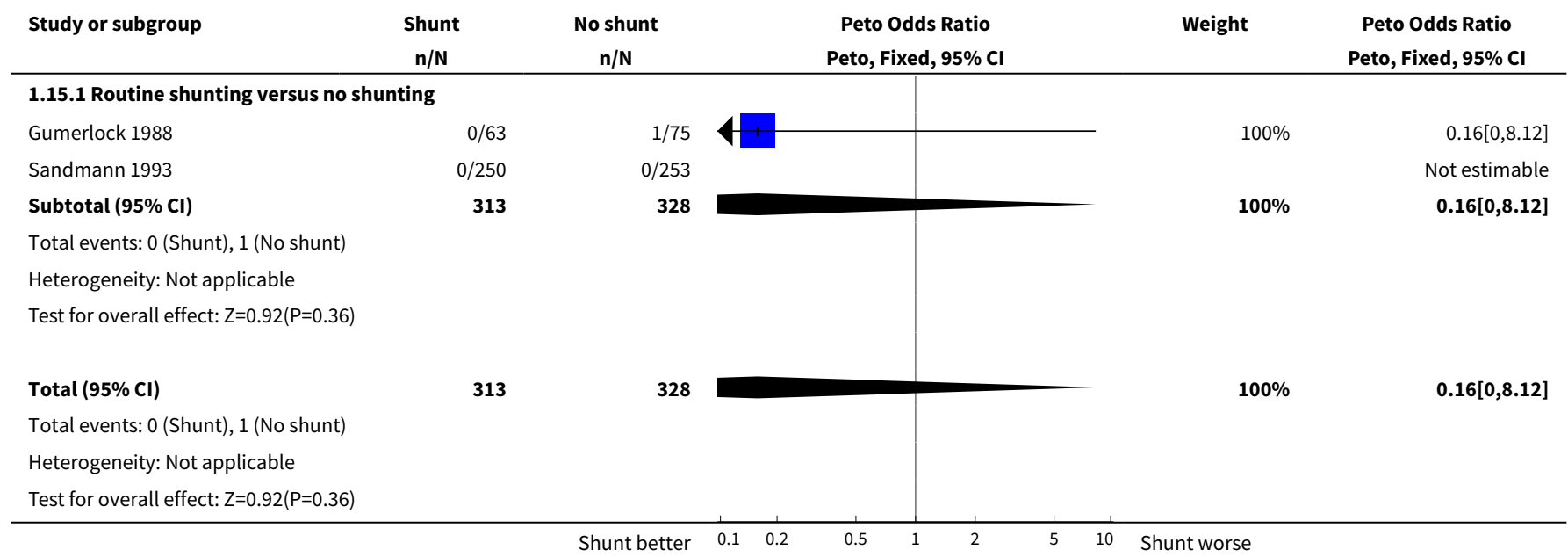

Analysis 1.16. Comparison 1 Shunting (routine or selective) versus no shunting, Outcome 16 Nerve palsy post-operatively.

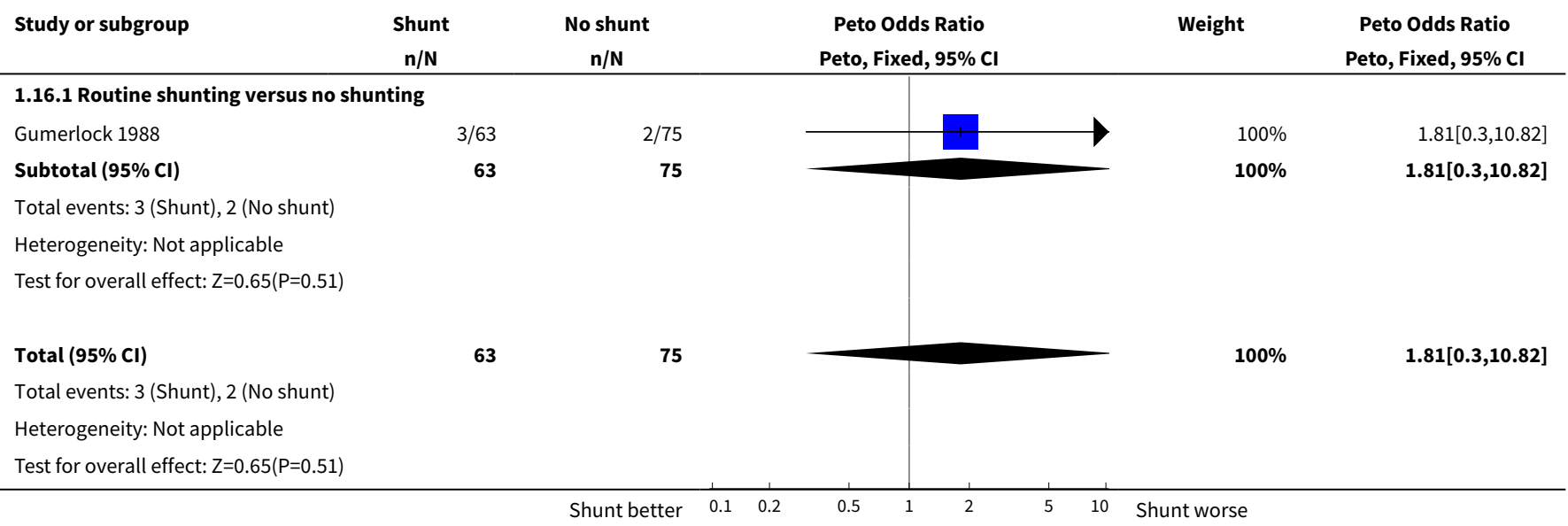

\section{APPENDICES}

\section{Appendix 1. MEDLINE search strategy}

MEDLINE 2008 to 2013

Term used "carotid endarterectomy"

MEDLINE (Ovid) 2008 to 2013 and Cochrane Central Register of Controlled Trials (lines 1 to 12)

1 Endarterectomy, carotid/

2 exp carotid arteries/su (surgery)

3 exp carotid artery diseases/su

4 exp carotid arteries/

5 exp carotid artery diseases/

6 carotid.tw.

Routine or selective carotid artery shunting for carotid endarterectomy (and different methods of monitoring in selective shunting) 
74 or 5 or 6

8 endarterectomy/

9 (endarterectom\$ or surg\$).tw.

108 or 9

117 and 10

121 or 2 or 3 or 11

13 randomized controlled trial.pt.

14 randomized controlled trials as topic/

15 controlled clinical trial.pt.

16 controlled clinical trials as topic/

17 random allocation/

18 clinical trial.pt.

19 exp clinical trials as topic/

20 (clin\$ adj25 trial\$).tw.

21 random $\$$.tw.

22 research design/

23 intervention studies/

24 control\$.tw.

25 shunt\$.tw.

26 or $/ 13-25$

2712 and 26

28 limit 27 to humans

Appendix 2. EMBASE search strategy

\section{EMBASE 2008 to 2013}

Terms used "carotid endarterectomy" and "carotid surgery"

\section{EMBASE (Ovid) 2008 to 2013}

1 carotid endarterectomy/

2 carotid artery surgery/

3 exp carotid artery disease/su

4 exp carotid artery/

5 exp carotid artery disease/

64 or 5

7 artery surgery/ or endarterectomy/ or vascular surgery/ or surgery/

86 and 7

9 (carotid adj5 (endarterect\$ or surgery)).tw.

101 or 2 or 3 or 8 or 9

11 Clinical trial/

12 randomized controlled trial/

13 controlled study/

14 randomization/

15 random\$.tw.

16 Prospective study/

17 "Evaluation and follow up"/ or Follow up/

18 versus.tw.

19 prospective.tw.

20 types of study/

21 methodology/

22 comparative study/

23 ((intervention or experiment\$) adj5 group\$).tw.

24 Parallel design/

25 intermethod comparison/

26 (controls or control group\$).tw.

27 (control\$ adj trial\$).tw.

28 shunting/ or shunt\$.tw.

29 or/11-28

3010 and 29

31 limit 30 to humans

Routine or selective carotid artery shunting for carotid endarterectomy (and different methods of monitoring in selective shunting) 
WHAT'S NEW

\begin{tabular}{lll}
\hline Date & Event & Description \\
\hline 9 August 2013 & $\begin{array}{l}\text { New citation required but conclusions } \\
\text { have not changed }\end{array}$ & New first author. \\
\hline 9 August 2013 & New search has been performed & $\begin{array}{l}\text { The searches have been updated and completed to August } \\
\text { 2013. We have identified and included two new randomised tri- } \\
\text { als, bringing the total number of included studies to six, involv- } \\
\text { ing 1270 participants. The conclusions of the review have not } \\
\text { changed. }\end{array}$ \\
\hline
\end{tabular}

\section{H I S T O R Y}

Protocol first published: Issue 1, 1995

Review first published: Issue 1, 1995

\begin{tabular}{|c|c|c|}
\hline Date & Event & Description \\
\hline 3 May 2009 & New search has been performed & $\begin{array}{l}\text { The searches have been updated and completed to Novem- } \\
\text { ber 2008. In the years since the searches were last completed } \\
\text { in 2000, we have identified one new randomised trial (Palombo } \\
\text { 2007), which assesses the effect of shunting versus non-shunt- } \\
\text { ing during carotid endarterectomy. This new trial involved } 48 \text { pa- } \\
\text { tients in each group and there were no outcome events in either } \\
\text { group. In this updated version, the conclusions have not there- } \\
\text { fore changed materially from the previous review. }\end{array}$ \\
\hline
\end{tabular}

\begin{tabular}{lll}
\hline 3 May 2009 & $\begin{array}{l}\text { New citation required but conclusions } \\
\text { have not changed }\end{array}$ & Change of authorship. \\
\hline 12 September 2008 & Amended & Converted to new review format. \\
\hline 10 August 2001 & New search has been performed & $\begin{array}{l}\text { In the six years since this review was first published there have } \\
\text { been a number of retrospective comparisons of selective shunt } \\
\text { use versus systematic shunt use, as well as a prospective com- } \\
\text { parison of different shunt types, but there have been no new } \\
\text { prospective randomised controlled trials relevant to this review. }\end{array}$
\end{tabular}

\section{CONTRIBUTIONS OF AUTHORS}

\section{Update of review}

Wilaiwan Chongruksut, Tanat Vaniyapong, Kittipan Rerkasem: designed the protocol, performed searches, selected studies for inclusion or exclusion, extracted data and updated the review.

\section{DECLARATIONS OF INTEREST}

None known.

\section{SOURCES OF SUPPORT}

\section{Internal sources}

- Faculty of Medicine, Chiang Mai University, Thailand.

Routine or selective carotid artery shunting for carotid endarterectomy (and different methods of monitoring in selective shunting) 
- Reserach Institute for Health Sciences, Chiang Mai University, Chiang Mai, Thailand.

\section{External sources}

- Stroke Prevention Research Unit, Nuffield Department of Clinical Neurosciences, University of Oxford, UK.

- Thailand Research Fund, Thailand.

\section{DIFFERENCES BETWEEN PROTOCOLANDREVIEW}

None.

\section{NOTES}

None.

\section{N DEX TERMS}

\section{Medical Subject Headings (MeSH)}

Blood Pressure Determination [methods]; Carotid Arteries [physiology] [*surgery]; Electroencephalography [methods];

Endarterectomy, Carotid [adverse effects] [ ${ }^{*}$ methods]; Intraoperative Complications [prevention \& control]; Randomized Controlled Trials as Topic; Stroke [etiology] [prevention \& control]

\section{MeSH check words}

Humans 